\title{
A brief review of data-driven ICME for intelligently discovering advanced structural metal materials: Insight into atomic and electronic building blocks
}

\author{
William Yi Wang ${ }^{1, a)}$ (D), Bin Tang ${ }^{1}$, Deye Lin² ${ }^{2}$, Chengxiong Zou ${ }^{1}$, Ying Zhang ${ }^{1}$, Shun- \\ Li Shang ${ }^{3}$, Quanmei Guan ${ }^{4}$, Jun Gao ${ }^{4}$, Letian Fan ${ }^{4}$, Hongchao Kou ${ }^{1}$, Haifeng Song ${ }^{2}$, Jijun Ma ${ }^{4}$, \\ Xi-Dong Hui ${ }^{5}$, Michael C. Gao ${ }^{6, b)}$, Zi-Kui Liu ${ }^{3}$, Jinshan Li ${ }^{1}$ \\ ${ }^{1}$ State Key Laboratory of Solidification Processing, Northwestern Polytechnical University, Xi'an, Shaanxi 710072, China \\ ${ }^{2}$ CAEP Software Center for High Performance Numerical Simulation, Institute of Applied Physics and Computational Mathematics, Beijing 100088, China \\ ${ }^{3}$ Department of Materials Science and Engineering, The Pennsylvania State University, University Park, Pennsylvania 16802, USA \\ ${ }^{4}$ R $D$ Center, CRRC Tangshan Co., Ltd., Tangshan 063035, China \\ ${ }^{5}$ State Key Laboratory for Advanced Metals and Materials, University of Science and Technology Beijing, Beijing 100083, China \\ ${ }^{6}$ Leidos Research Support Team, National Energy Technology Laboratory, Albany, Oregon 97321, USA \\ ${ }^{a}$ Address all correspondence to this author. e-mail: wywang@nwpu.edu.cn \\ b) This author was an editor of this journal during the review and decision stage. For the JMR policy on review and publication of manuscripts authored \\ by editors, please refer to http://www.mrs.org/editor-manuscripts/. \\ This paper has been selected as an Invited Feature Paper.
}

Received: 13 December 2019; accepted: 3 February 2020

This article presents a brief review of our case studies of data-driven Integrated Computational Materials Engineering (ICME) for intelligently discovering advanced structural metal materials, including light-weight materials ( $\mathrm{Ti}, \mathrm{Mg}$, and $\mathrm{Al}$ alloys), refractory high-entropy alloys, and superalloys. The basic bonding in terms of topology and electronic structures is recommended to be considered as the building blocks/units constructing the microstructures of advanced materials. It is highlighted that the bonding charge density could not only provide an atomic and electronic insight into the physical nature of chemical bond of materials but also reveal the fundamental strengthening/embrittlement mechanisms and the local phase transformations of planar defects, paving a path in accelerating the development of advanced metal materials via interfacial engineering. Perspectives on the knowledge-based modeling/simulations, machine-learning knowledge base, platform, and nextgeneration workforce for sustainable ecosystem of ICME are highlighted, thus to call for more duty on the developments of advanced structural metal materials and enhancement of research productivity and collaboration.

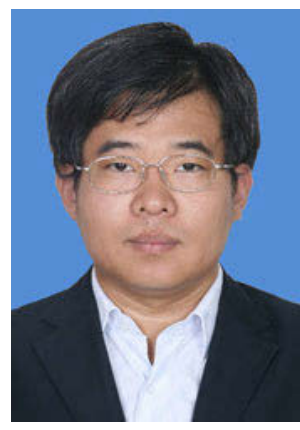

William Yi Wang
William Yi Wang received his M.S. and Ph.D. in Materials Science and Engineering from the Pennsylvania State University in 2012 and 2013 and continuously worked as a postdoctoral fellow advised by Professor Zi-Kui Liu till May 2016. Afterward, he joined the School of Materials Science at Northwestern Polytechnical University in 2016 as an associate professor. Professor Wang's research topic is the Data-Driven ICME for Advanced Materials. Through revealing the composition-processing-microstructure-properties relationship, the time and the cost will be reduced during the development of new materials, which is the motivation of his research activities. He received the scholarship and best poster award at Gordon Research Conference (2010), the scholarship at the 1st TMS-ICME conference (2011), the TMS-LMD Best Graduate Student (2012) and Young Professional (2015) poster awards, the ACerS Nuclear \& Environmental Technology Division (NETD) Travel Grant and Graduate Excellence in Materials Science (GEMS) Diamond Award (2012), the CALPHAD Scholarship (2012), the Stiftelsen för Tillämpad Termodynamik grant from KTH Royal Institute of Technology (2013), the Bayer Travel Fund from PSU (2013), and the "Rising Stars in Computational Materials Science Finalist" raised by the Journal of Computational Materials Science (2019). He has authored and co-authored more than 60 publications in respectable peer-reviewed journals, including Advanced Materials, Acta Materialia, npj Computational Materials, Materials Research Letters, Engineering, and Computational Materials Science, several of which were selected as cover images. Additionally, he has co-authored 1 book chapter in "ICME for Metals: Concepts and Case Studies" and applied more than 10 patents together with his collaborators. 


\section{Introduction}

With the dramatic achievements and significant progresses in the last decade, Integrated Computational Materials Engineering (ICME) provides an unparalleled designing and manufacturing paradigm in accelerating the $\mathrm{R} \& \mathrm{D}$ of advanced materials $[1,2,3,4,5]$. It is recognized that recent advances in superpower computation [6], additive manufacturing [7, 8], big data [9], data mining [10], machine learning [10, 11, 12], cloud computation [13], metallic materials ontology [14], graphic knowledge $[15,16]$, and so on, provide an opportunity to create a designing and manufacturing paradigm shift. For instance, the high-throughput-type and the combinatorial approaches integrating both the bottom-up designing and the top-down engineering set up the digital twin feature of compositionprocessing-structure-property-performance (CPSPP) workflow process at multiscales [17, 18, 19, 20, 21, 22, 23], which is known as the data-driven ICME [2]. The advanced structural metal materials are developed/manufactured crossing multiscales, from Electronics to Phases [24, 25], i.e., from Atom to Autos [26], from CALPHAD to Flight [27]. Moreover, to lead the world in scientific and technological innovations, global competitors have launched various strategies/programs and boosted the development of new manufacturing technologies, which include the Materials Genome Initiative (MGI) [28] and the Advanced Manufacturing of United States [29], the China's Materials Genome Engineering (MGE) \& Made in China 2025 [30], the European Union's Industry 4.0 Programme [31], the Industry 2050 of United Kingdom [32], the Intelligence Manufacturing System 2020 (IMS2020) \& Toward Technology Innovation of Society 5.0 of Japan, the Industry Innovation 3.0 of Korea, and so on [2]. In fact, more than four decades ago, the combinational approaches involving high-throughput synthesis and characterization of multiple-alloy compositions have been utilized in materials sciences, to rapidly determine phase diagrams in multicomponent spaces and screened physical and mechanical properties [33, 34].

Recently, we discussed the frameworks of data-driven ICME in the last two years, presenting key aspects of principles, benchmarks, standards, databases, platforms, and toolkits via various case studies [2]. A universal format of Data Identifier (DID) code consisting of a set of Build Chains is proposed [35], which is in line with the classical form of identifier utilized in both international and national standards and can serve the Inheritable Integrated Intelligent Manufacturing $\left(\mathrm{I}^{3} \mathrm{M}\right)$. It is worth mentioning that the inheritable feature indicates the original concept of "Materials Genome" in the materials discovery/design/manufacturing. In this article, a brief review of our case studies of data-driven ICME for intelligently discovering advanced structural metal materials is presented, which include the light-weight materials ( $\mathrm{Ti}, \mathrm{Mg}$, and $\mathrm{Al}$ alloys), refractory high-entropy alloys (RHEAs), and superalloys for high temperature applications. The basic bonding in terms of topology and electronic structures is recommended to be considered as the building blocks/units constructing the microstructures of advanced materials, known as the so-called Materials Genome. It is highlighted that the bonding charge density could not only provide an atomic and electronic insight into the physical nature of chemical bond of materials but also reveal the fundamental strengthening/embrittlement mechanism and the local phase transformations of planar defects, paving a path in accelerating the development of advanced metal materials via interfacial engineering approach. Perspectives on the knowledge-based modeling/simulations, machine-learning knowledge base, platform, and next-generation workforce for sustainable ecosystem of ICME are highlighted, thus to call for more duty on the developments of advanced structural metal materials and enhancement of research productivity and collaboration.

\section{Methodologies}

\section{Digital twin design paradigm at ICME era}

Toward the novel design paradigm in ICME era, the CPSPP relationship/workflow process displays a digital twin feature, indicating that there is digital world designing/manufacturing the advanced materials, as shown in Fig. 1. Each experimental process in terms of top-down design can be matched in the theoretical one defined as the bottom-up design, which basically presents the foundation of combinatorial approach integrating the advanced technologies, such as high-throughput computations, data mining, machine learning, intelligent/additive manufacturing, cloud computation, and internet of things $[31,36,37]$. Moreover, referring to those three aspects of MGI infrastructures, a Human-Cyber-Physics system (HCP) has been proposed and emphasized in the frames of MGE and Made in China 2025 [30], which is as same as the CyberPhysical-Social ecosystem reported to U.S. NASA Scientific and Technical Information Program. Both of them will play a key role in accelerating the model-based/knowledge-based concurrent design, development, and deployment of materials and systems throughout the product life cycles [2, 35, 36]. While the interaction of Human-Cyber indicates the importance of knowledge-based computations/design, the interactions of Human-Physics and Cyber-Physics highlight key roles of the high-throughput manufacturing/experimental validations and the artificial intelligence/machine learning in the HCPs. It is expected that digital design and intelligent manufacturing could be improved dramatically through the digital twin design paradigm.

Furthermore, shown as the Atom-to-Product processing chain of Ti alloys in Fig. 1, it can be seen that integrated various 


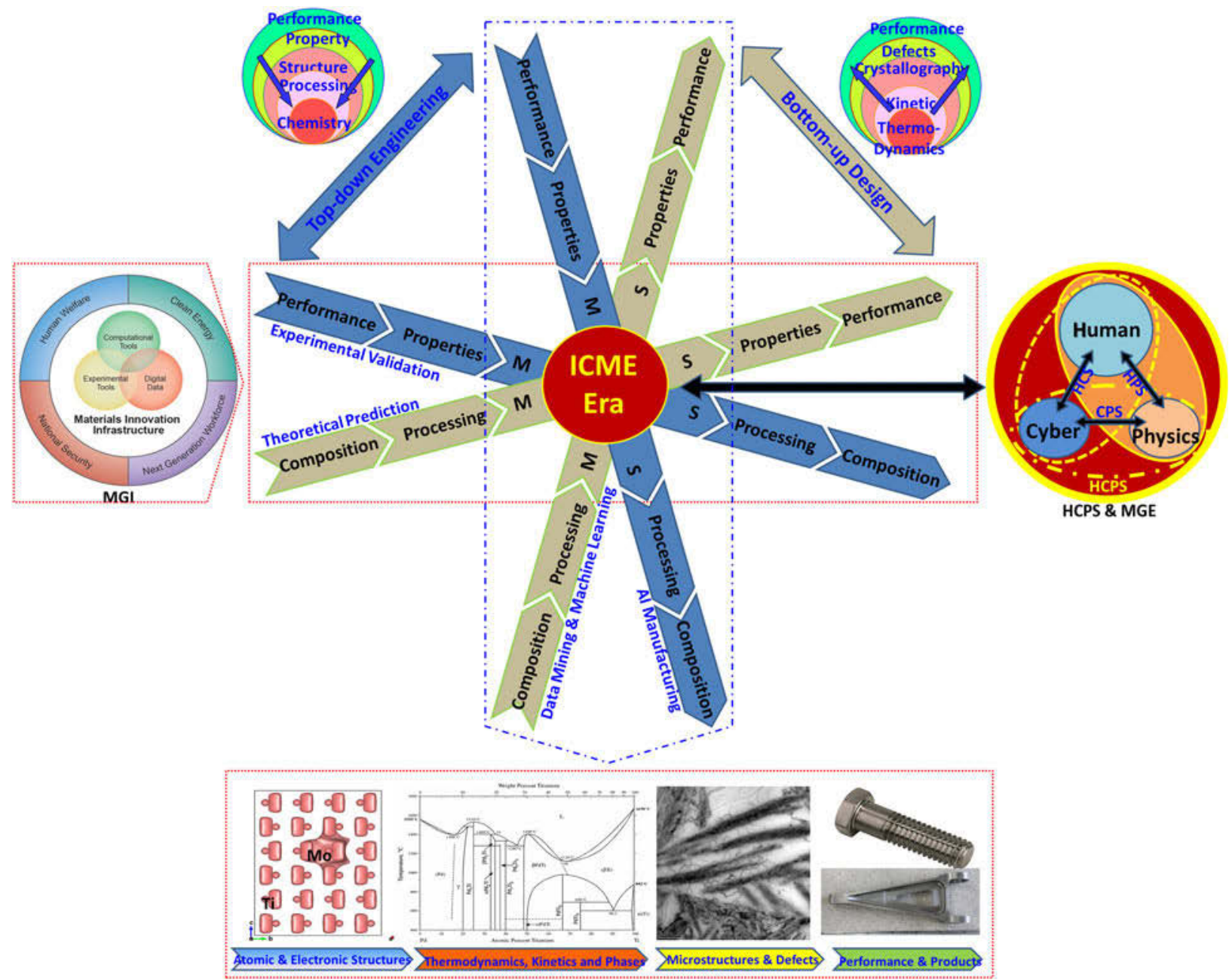

Figure 1: Atom-to-Product processing chain of Ti alloys in line with the digital-twin design paradigm in ICME Era [2]

theoretical and experimental approaches at multiscales will be essential to fabricate a high-quality product with a novel composition and reduced designing time and cost. Actually, the letter "I" in ICME highlights a crucial element needed for implementing the predictive models and simulations into materials design and development across the product-development cycle, in which the bottlenecks are related to the need for the development of new fundamental theoretical methodologies and frameworks for linking atomistics, microstructure, processing, and property models across length and time scales [38]. Modeling/simulation for composition optimization/ design, structure analysis/characterization, physics-based performance (structures), and manufacturing can be accelerated by the multiscale calculations, including density functional theory (DFT) calculations, ab initio molecular dynamics (AIMD), classical MD simulations, CALculated PHAse Diagram (CALPHAD) modeling, phase-field simulations, and (kinetic) Monte Carlo simulations.

In fact, based on the density functional theory, highthroughput first-principles calculations can not only provide the thermodynamic properties combined with CALPHAD but also support kinetic properties, mechanical properties, and other fundamental physical properties, as shown in Fig. 2. Those properties also indicate their further contributions in the multiscale modeling or computations together with the corresponding crossover experimental validations. It is worth mentioning that various kinds of databases have boosted with the significant enhancement of computational power and investigations of research efforts/supports, which is one third of the key Materials Genome infrastructures. The multiscale computational materials science, open source cyber infrastructure for data management, and an integrated approach combining computation and experiments to accelerate the development of advance materials have become three significant research fields $[41,42]$. Together with the foundations and milestones of MGI/MGE and ICME, the recent progresses emphasizing on the importance of computational materials/ platform/system for the future have been released [24, 36, 39, 40, 43]. Materials Genome has been recommended as a set of databases (information) for predicting materials properties of 


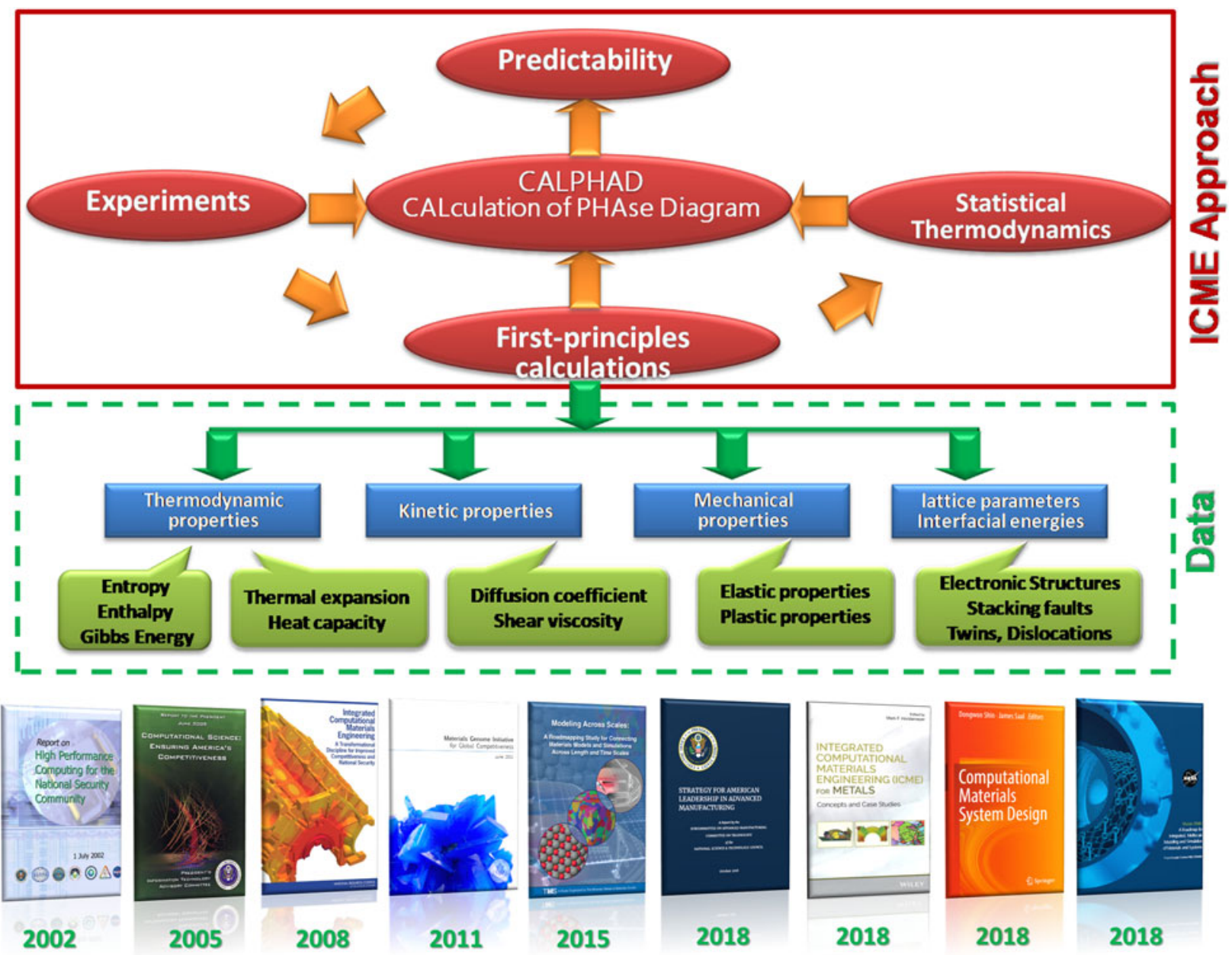

Figure 2: The proposed data-driven ICME approach [2, 24] together with the corresponding foundations and milestones [24, 36, 39, 40].

virtual alloy compositions and its response to processing and usage conditions [44]. Moreover, data-the basic unit building block of database and advanced computational algorithms such as machine learning, data mining, deep learning, and artificial intelligence-have been recognized as the third essential digital resource in the $I^{3} \mathrm{M}$ beside the natural mineral materials and the financial funds. The flow chain of "Data-Cyber-KnowledgeWisdom" presents the inheritable feature of the data in the frameworks of "Materials Genome," which is also highlighted in the Data-driven ICME designing paradigm of advanced materials.

\section{Electrons to phases and properties: key roles of microstates}

Since the structure dominates the properties and performance in the CPSPP workflow process, the structure predictions and characterization play a key role in accelerating the discovery of advanced materials in a cost-effective approach. Predicting crystal structures with data mining of quantum calculations (i.e., high-throughput electronic structure calculations together with structural data mining algorithm or phenomenological models) allows the identification of new materials $[45,46,47$, 48]. It should be highlighted that the atomic and electronic basis for the fundamental strengthening mechanisms and the physical nature of chemical bonds can be revealed comprehensively by bonding charge density [2]. On the one hand, the hidden topological orders or short-range orders (SRO) or clusters or microstates should be considered when constructing the structures of multicomponent alloys theoretically and experimentally. The microstates/configurations/local orders are essential to reveal their structure-property relationship $[49,50,51,52]$. Predictive models have been proposed to reveal the hydrogen trapping and bubbling in nanovoids in bodycentered-cubic (BCC) metals, which integrate the multiscale calculations including DFT calculations, classical MD simulations, and kinetic Monte Carlo simulations [53]. The microstates/clusters dominated shear bands or serrations of high-entropy alloys and metallic glasses during deformation are reported [51, 54]. On the other hand, "defects at the atomic scale, which are revealed in the electronic structure, affect the macroscopic mechanical properties 
such as the elastic and plastic deformation," which is highlighted in the review of Four Decades of Materials Developments Transform Society reported by Philip Ball [55]. It is recommended that correlations between structural defects and local phase transformations should be considered $[56,57,58,59]$, especially when designing novel advanced materials via the Grain-boundary Engineering or Interface Engineering approach. For instance, in the view of bonding charge density, the local phase transformation of several kinds of planar faults has been captured/reported, such as the connections between stacking faults (growth fault-I1, deformation fault-I2, and extrinsic fault-EF) and long periodic stacking ordered structures/phases (LPSOs) of Mg alloys [56], the local FCC-HCP transformation in the grain boundary of Fe and $\mathrm{Al}$ alloys $[60,61]$, the local $\mathrm{DO}_{23}$ and $\mathrm{D}_{22}$ phase transformations in superlattice intrinsic stacking fault (SISF), and antiphase boundaries (APBs) of superalloys [57, 62].

Moreover, with the guidance of the electron redistributions in terms of bonding charge density $[56,65,66,67]$ and electron localization functions $[68,69]$, new insights are provided into those microstates/SROs/clusters and structural phase transformations quantitatively and qualitatively. They are utilized to reveal the physical nature of chemical bond of pure metals (Al $[61,70], \mathrm{Ag}[71], \mathrm{Fe}[60,72], \mathrm{Mg}, \mathrm{Ti}[73,74]$ ), alloys (Co-based $[57,62]$ and Ni-based [75]alloys), Fe-X alloys [60, 72], Mg-RETM alloys [67, 76], RHEAs [49, 51], Ti-X alloys [73, 74]), metal melts (vit1 metallic glass [51], Al-Cu [77]), oxides ( $\mathrm{AgO}$ [71],
$\mathrm{Ag}_{2} \mathrm{O}$ [71], $\mathrm{Ag}_{7} \mathrm{O}_{8} \mathrm{NO}_{3}$ [78], and $\mathrm{Fe}_{3} \mathrm{O}$ ), semiconductors (graphene [65], sulfur [79], sulfides [79], and $\mathrm{SiC}$ [80]), and structural defects (stacking faults [62, 73, 81], APBs [57, 75], grain boundaries $[61,72]$, and dislocations $[82,83])$, which also reveal the fundamental solid-solution strengthening/embrittlement mechanism $[61,73]$ and the grain refinement mechanism $[70,74]$

Furthermore, beyond those aforementioned properties discussed in Fig. 2, other principles have been proposed in predicting the mechanical properties of pure metals and alloys based on the electronic properties, such as electron work function (EWF) [63] and valence electron concentration (VEC) [64], as shown in Fig. 3. It has been reported that supertoughening in B1 transition metal nitride alloys occurs through VEC tuning [84]. VEC has been considered as an essential training parameter in discovering new advanced high-entropy alloys. We believe that, aiming at the mechanical properties, predictions based on density functional theory [85] via WEF would result in a more reliable result with physical foundations. For example, the power-law scaled properties including yield strength, hardness, elastic constant, and shear/bulk/Young's modulus of pure metals and alloys have been validated. Referring to the VEC, the advantage of EWF is that these elements in the same group of elemental periodic table can be distinguished. Thus, EWF will be more suitable than VEC to be considered as one kind of key

\begin{tabular}{|c|c|c|c|c|c|c|c|c|c|c|c|c|c|c|c|c|}
\hline IA & IIA & \multicolumn{2}{|c|}{ Min } & & & & & & & \multicolumn{2}{|c|}{ Max } & IIIA & IVA & VA & VIA & VIIA \\
\hline Lì & $\mathrm{Be}$ & & & & & \multirow{2}{*}{\multicolumn{2}{|c|}{ Element }} & & & & & B & C & \multirow[t]{2}{*}{$\mathbf{N}$} & \multirow[t]{2}{*}{0} & \multirow[t]{3}{*}{$\mathbf{F}$} \\
\hline 2.9 & 4.98 & & & & & & & & & & & 4.45 & 5 & & & \\
\hline 1 & 2 & & & & & \multicolumn{2}{|c|}{ EWF } & & & & & 3 & 4 & 5 & 6 & \\
\hline $\mathrm{Na}$ & $\mathrm{Mg}$ & & & & & \multicolumn{2}{|c|}{ VEC } & & & & & Al & Si & \multirow[t]{2}{*}{ P } & \multirow{2}{*}{ 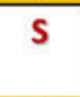 } & \multirow[t]{3}{*}{ Cl } \\
\hline 2.75 & 3.66 & & & & & \multirow{2}{*}{\multicolumn{2}{|c|}{ VIIB }} & & & & & 4.28 & 4.85 & & & \\
\hline 1 & 2 & IIIB & IVB & VB & VIB & & & VIIIB & & IB & $\| B$ & 3 & 4 & 5 & 6 & \\
\hline $\mathrm{K}$ & $\mathrm{Ca}$ & Sc & Tì & V & $\mathrm{Cr}$ & $\mathrm{Mn}$ & $\mathrm{Fe}$ & Co & $\mathbf{N i}$ & $\mathrm{Cu}$ & $\mathrm{Zn}$ & Ga & $\mathrm{Ge}$ & As & $\mathrm{Se}$ & \multirow[t]{3}{*}{$\mathrm{Br}$} \\
\hline 2.3 & 2.87 & 3.5 & 4.33 & 4.3 & 4.5 & 4.1 & 4.5 & 5 & 5.15 & 4.65 & 4.33 & 4.2 & 5 & 3.75 & 5.9 & \\
\hline 1 & 2 & 3 & 4 & 5 & 6 & 7 & 8 & 9 & 10 & 11 & 12 & 3 & 4 & 5 & 6 & \\
\hline $\mathbf{R b}$ & $\mathrm{Sr}$ & $Y$ & $\mathrm{Zr}$ & $\mathrm{Nb}$ & Mo & \multirow[t]{2}{*}{ TC } & $R u$ & Rh & Pd & $\mathrm{Ag}$ & $\mathrm{Cd}$ & In & Sn & Sb & $\mathrm{Te}$ & \multirow[t]{3}{*}{ I } \\
\hline 2.16 & 2.59 & 3.1 & 4.05 & 4.3 & 4.6 & & 4.71 & 4.98 & 5.12 & 4.26 & 4.22 & 4.12 & 4.42 & 4.55 & 4.95 & \\
\hline 1 & 2 & 3 & 4 & 5 & 6 & 7 & 8 & 9 & 10 & 11 & 12 & 3 & 4 & 5 & 6 & \\
\hline Cs & $\mathrm{Ba}$ & & $\mathrm{Hf}$ & $\mathrm{Ta}$ & $w$ & $\operatorname{Re}$ & Os & Ir & Pt & $\mathrm{Au}$ & $\mathrm{Hg}$ & $\mathrm{TI}$ & $\mathbf{P b}$ & $\mathrm{Bi}$ & \multirow[t]{2}{*}{ Po } & \multirow[t]{3}{*}{ At } \\
\hline 2.14 & 2.7 & & 3.9 & 4.25 & 4.55 & 4.96 & 4.83 & 5.27 & 5.65 & 5.1 & 4.49 & 3.84 & 4.25 & 4.22 & & \\
\hline \multirow[t]{4}{*}{1} & 2 & & 4 & 5 & 6 & 7 & 8 & 9 & 10 & 11 & 12 & 3 & 4 & 5 & 6 & \\
\hline & & La & $\mathrm{Ce}$ & $\mathrm{Pr}$ & $\mathrm{Nd}$ & $\mathrm{Pm}$ & $\mathrm{Sm}$ & $\mathrm{Eu}^{\#}$ & Gd & Tb & Dy & $\mathrm{Ho}$ & Er & $\mathrm{Tm}$ & $\mathrm{Yb}^{\#}$ & Lu \\
\hline & & 3.5 & 2.9 & 2.96 & 3.2 & 3.21 & 2.7 & 2.5 & 3.1 & 3 & 3.25 & 3.22 & 3.25 & 3.1 & 2.95 & 3.3 \\
\hline & & 3 & 3 & 3 & 3 & 3 & 3 & 3 & 3 & 3 & 3 & 3 & 3 & 3 & 3 & 3 \\
\hline $\mathrm{Fr}$ & $\mathbf{R a}$ & Ac & Th & $\mathbf{P a}$ & $\mathbf{U}$ & $\mathrm{Np}$ & $\mathrm{Pu}$ & $\mathrm{Am}$ & $\mathrm{Cm}$ & Bk & Cf & Es & \multirow[t]{3}{*}{$\mathrm{Fm}$} & \multirow[t]{3}{*}{ Md } & \multirow[t]{3}{*}{ No } & \multirow[t]{3}{*}{$\mathbf{L r}$} \\
\hline $2.01^{*}$ & $2.78^{*}$ & $3.38^{*}$ & 3.44 & 3.76 & 3.85 & 4 & 3.98 & 3.32 & 3.32 & 3.37 & 3.38 & 2.88 & & & & \\
\hline 1 & 2 & 3 & 3 & 3 & 3 & 5 & 4 & 3 & 3 & 3 & 3 & 2 & & & & \\
\hline
\end{tabular}

Figure 3: The periodic table of pure elements [51] with the corresponding EWF [63] and VEC [64]. 
principles designing new multicomponent alloys. Several cases studies are discussed in detail in the results and discussion.

\section{Results and discussions}

\section{Ti alloys}

Because of their good strength-to-weight ratio, high melting temperature, good corrosion resistance, and excellent biocompatibility, Ti alloys are widely applied in the structural materials in aerospace, automotive, and biomedical applications [73, 86, 87]. It is understood that the fundamental understanding of the effect of solute atoms on the lattice distortion and deformation behaviors of Ti alloys is critical to improve their strength and ductility in the development of advanced high-strength $\mathrm{Ti}$ alloys and their corresponding products. Here, we briefly present an Atom-to-Product routine via the multiscale simulations integrated with experimental validations when optimizing the properties of highstrength Ti alloys, the method of which is in line with the digital twin feature of CPSPP, shown in Figs. 3 and 4. Based on the elemental periodic table of bonding charge density $(\Delta \rho)$ of HCP Ti-X alloys displayed in Fig. 3(a), the coupling effects of valence electron and lattice distortion of solute atoms on the bond structures and bond morphologies are presented obviously, which reveal the atomic and electronic basis of the solid-solution strengthening mechanism of those atoms with higher value of $\Delta \rho$. It is understood that a higher of value of $\Delta \rho$ leads to a stronger bonding.

With the aid of data mining or machine learning algorithm, new principles/criteria could be obtained for designing the novel $\mathrm{Ti}$ alloys applied in specific conditions (i.e., high load or high temperature). In particular, the fundamental properties can be predicted by high-throughput first-principles calculations shown in Fig. 3(b), which construct the foundation of data mining.

The best candidate Ti alloys with either high-strength and ductility or low steady-state creep rate can be screened out via proper criteria. In the view of web chart of physical properties of Ti-X alloys, the key parameters affecting these target properties can be distinguished, which are essential to address the model/relation. For example, the reduction of stacking fault energy (ESF) will improve the creep resistance of the materials [88], which could be treated as a critical principle during designing of the high-temperature Ti alloy with good creep resistance. As for the development of ductile highstrength $\mathrm{Ti}$ alloys, the c/a ratio, ESF, dislocation width/ density, and EWF are recommended to be considered as important criteria. The reasons are (i) the $c / a$ ratio of $\mathrm{HCP} \mathrm{Ti}$ is lower than the ideal one (1.633) and results in the most favorable slip systems consisting of the prismatic and the basal planes [89] since the axial ratio (i.e., $c / a$ ratio) significantly affects the variation of twinning shear in $\mathrm{HCP}[73,90]$; (ii) the $B / G$ ratio (1.75) has been recognized to be an identifier separating the ductile and brittle behavior [73, 89]; (iii) the deformation modes of twinning and slip are closely related to the stacking faults and the mobility of the dislocation is highly pertinent to the ESF [73, 91, 92]; and (iv) a lower ESF corresponds to a large distance between dissociated partial dislocations improving strength and ductility through enhancing a higher strain-hardening coefficient, lower twinning stress, and a higher twin propensity [73, 93, 94].

It is worth mentioning that several new designed Ti alloys are manufactured based on those aforementioned criteria, three
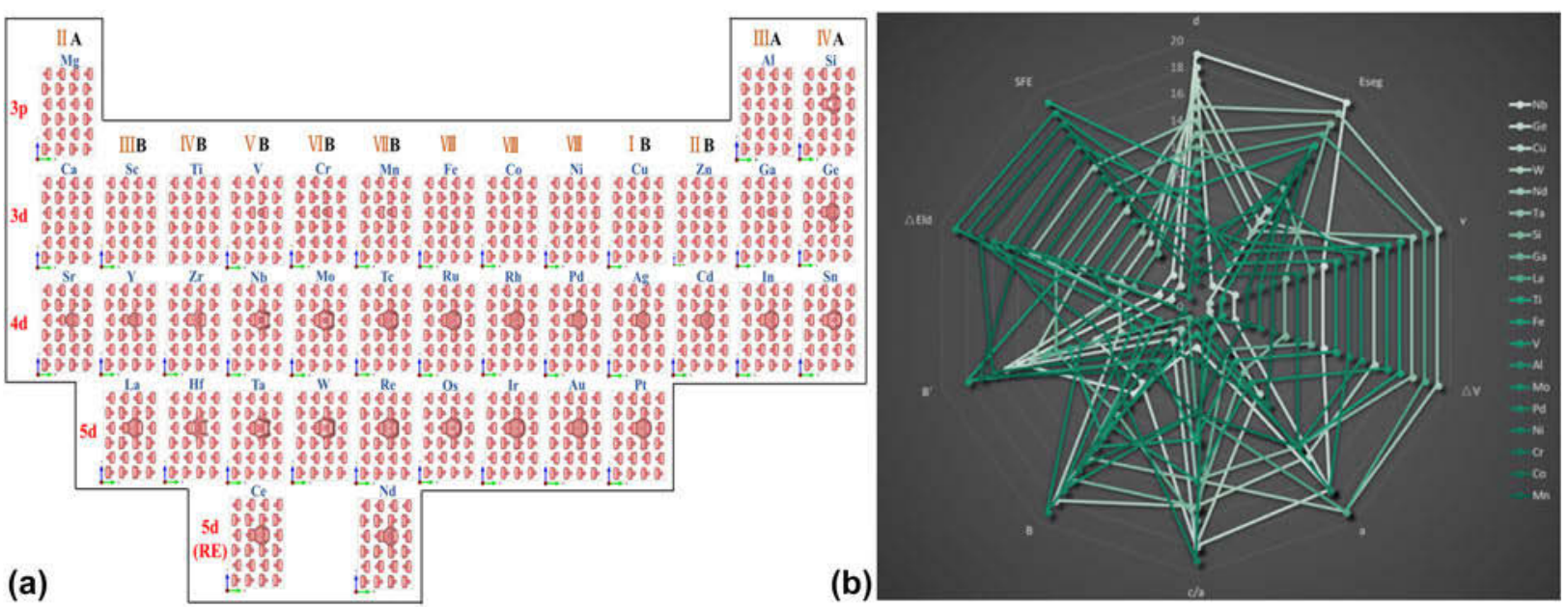

Figure 4: Databases and data mining of Ti-X alloys: (a) the elemental periodic table of bonding charge density of HCP Ti-X alloys and (b) web chart of physical properties of Ti-X alloys including lattice parameters ( $a$ and $c / a)$, bulk modulus $(B)$ together with it first derivative with pressure $\left(B^{\prime}\right)$, volume $(V)$ and its variation referring to $\mathrm{Ti}(\Delta V)$, lattice distortion energy $\left(\Delta E_{\mathrm{ld}}\right)$, stacking fault energy (SFE), dislocation width (d), and segregation energy to the fault layers of I2 ( $\left.E_{\text {seg }}\right)$. 
of which are named $\mathrm{Ti}-7333 \mathrm{~A}$, Ti-7443, and $\mathrm{Ti}-7543$, shown in Fig. 5. In fact, four main strengthening mechanisms should be considered when accurately predicting the yield strength of materials, including the solid-solution strengthening, grain refinement hardening, precipitation strengthening, and work hardening. Although only the solid-solution strengthening is considered, a strong linear correlation is addressed in Ti-7333A and Ti-7543 with the squared correlation coefficient $R^{2}=0.99$, shown in Fig. 5(a). On the contrary, the obvious diversity of Ti7433 from the line in Blue-Green-Red (BGR) gradient colors is attributed to the great amount of precipitations and grain refinement effect, which is also highlighted by the blue ellipse. Due to the absence of grain size information of the reported data listed in Fig. 5(a), it is hard to derive a proper model/ relation to reveal those strengthening mechanisms and the squared correlation coefficient $R^{2}$ is as low as 0.88 , presenting a large diversity. On the contrary, the coupling effect of solidsolution strengthening and grain refinement hardening of our designed Ti alloys are displayed in Fig. 5(b). The corresponding relation yields a good result, matching well with the experimental one. The large diversity of Ti-7543 is attributed to the great amount of precipitations. Therefore, it can be seen that the processing parameters to control grain size and screen composition are obtained to get the target yield strength of designed Ti alloys.

Figure 6 presents the digital-twin designing and manufacturing approaches for the new high-strength near $\beta$ Ti7333 landing gear torque arm, systematically exploring the microstructure evolution rules, establishing the constitutive models and microstructure models of hot deformation, and addressing the prediction of phase volume fraction, average grain size, dislocation density, and macro-physical fields during hot deformation. During the die forging of titanium alloy, the stress, strain, and temperature of different parts are different, which leads to the difference in microstructure of various parts. Since the microstructures of the alloy will dominate the performance in their service life, it is important to understand the microstructure evolution of titanium alloy under different process conditions. The finite element numerical simulation technology is used to simulate the material die forging process. The key point is to introduce the microstructure model into the die forging simulation, so that the grain size and phase volume fraction can be realized while observing the macroscopic physical field distribution. It can be seen that the model can accurately predict the average grain size and component size of the lower anti-torque arm of Ti-7333 alloy. By analyzing the macro-physical fields and the distribution of microstructure in the forging process, the process parameters of hot die forging and isothermal die forging of lower anti-torque arm can be well optimized. Accordingly, it is understood that the in the large deformation regions, dislocation density is high and grain size of $\beta$ phase is small. Compared with hot die forging, the differences of the temperature, $\beta$ grain size, and volume fraction of phases of workpiece will be reduced under isothermal die forging. In particular, increasing the deformation temperature and the pushing speed at the same time can reduce the differences of $\beta$ grain size of workpiece under hot die forging. On the contrary, improving deformation temperature and decreasing pushing speed and friction coefficient at the same time can reduce the differences of $\beta$ grain size and

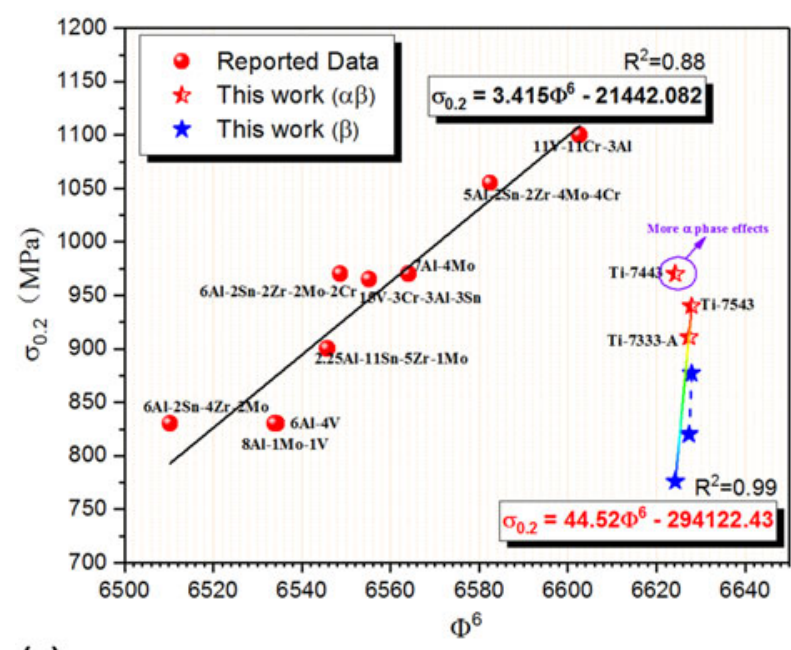

(a)

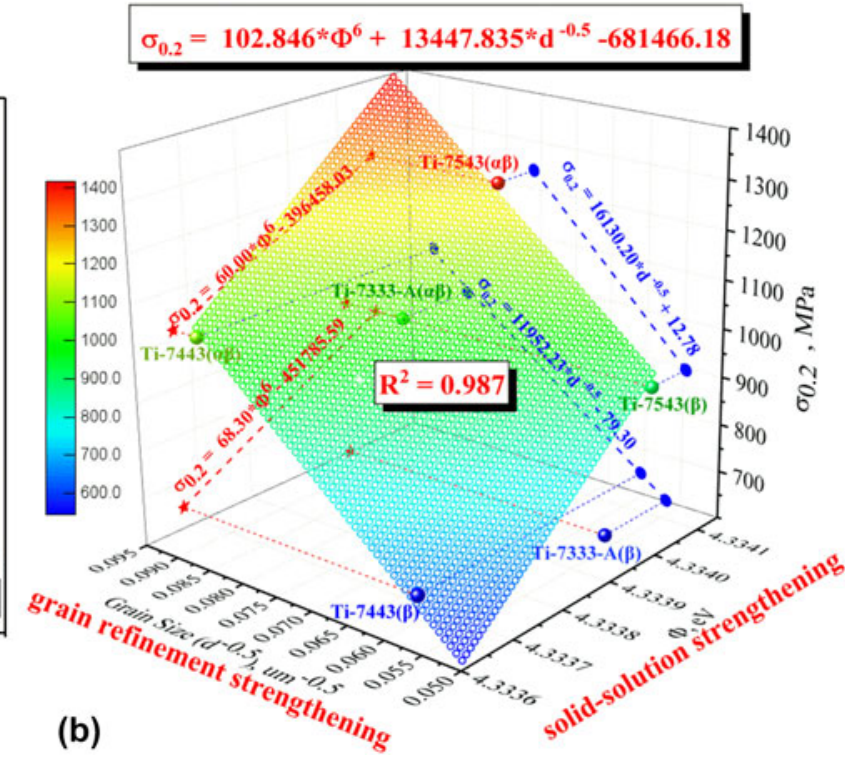

(b)

Figure 5: The predicted yield strength $\left(\sigma_{0,2}\right)$ of designed Ti alloys referring to relative Ti alloys: (a) power-law scaled $\sigma_{0.2}$ in terms of EWF ( $\left.\Phi\right)$ and (b) the coupling effect of solid-solution strengthening and grain refinement hardening of our designed Ti alloys. 


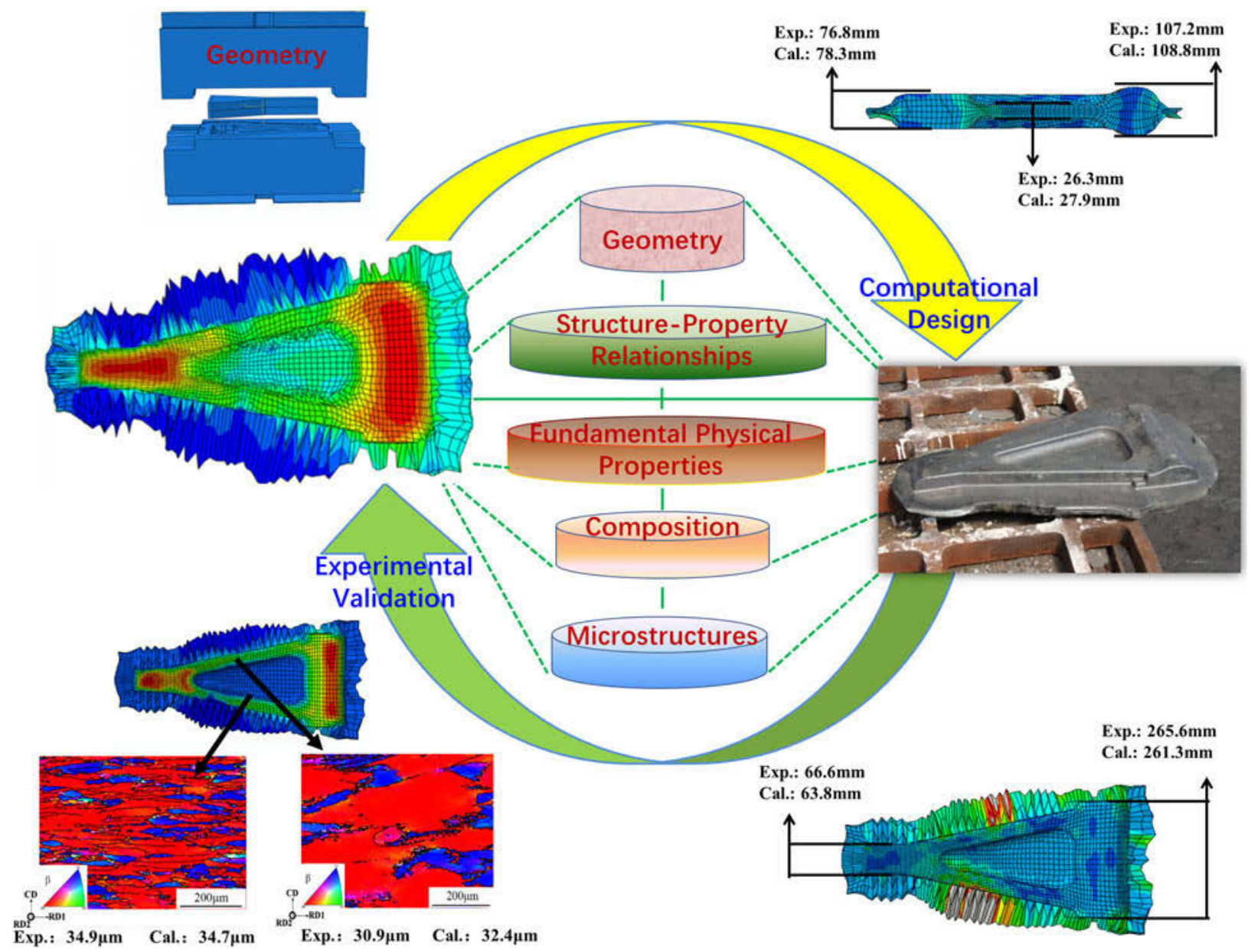

Figure 6: Digital-twin designing and manufacturing approaches for the Ti7333 landing gear torque arm.

volume fraction of $\alpha$ phase of workpiece under isothermal die forging.

\section{Mg alloys}

$\mathrm{Mg}$ and its alloys, being one kind of light-weight materials, are particularly attractive for transportation, electronic devices, and biocompatible/biodegradable applications [95]. One of the key challenges is to simultaneously improve their low-temperature ductility and strength $[95,96,97,98]$. As shown in Fig. 7, our previous works have comprehensively revealed the electronic and atomic basis for toughening and strengthening of $\mathrm{Mg}$ alloys via the interface engineering approach $[24,56,67,93,95$, 99, 100]. The local HCP-FCC phase transformations of SFs and LPSOs have been identified theoretically and experimentally by bonding charge density and high-resolution transmission microscope [95], both of which will enable the low-temperature ductility of Mg alloys $[67,101]$. The contributions of the local FCC-type fault layers to the thermodynamic properties and the bonding structures of $\mathrm{Mg}$ are revealed. It is noted that those elements highlighted in the periodic table by an abbreviation and blue background in Fig. 7 indicate the typical/classical solutes considered in the development/manufacturing of advanced $\mathrm{Mg}$ alloy. Accordingly, the effects of those solute atoms on the ESF, EWF, dislocation width, bonding structures, twinnability, and ideal strength are comprehensively studied $[93,95,100]$. Similarly, recent works have reported segregations and twin boundary pinning to strengthen Mg alloys [102, 103].

Moreover, lattice strain engineering has been considered as a key strategy in discovering advanced materials. Through yielding a local lattice distortion near solute atoms, a dislocation-free plastic deformation can form structural faults [95, 104]. Based on our proposed atomic array models in HCP structure, the severe lattice distortions mediate the HCP-toFCC transformation via atomic shuffling process, which is captured by the atomic trajectories from AIMD calculations [95]. That is the reasons why we proposed the strategy to strength the $\mathrm{Mg}$ alloys via the self-dispersed nano-lamellar faults [67]. It is understood that solute-induced lattice distortion can serve as one of many possible design principles for advanced Mg alloys, which is different from the classical shear 


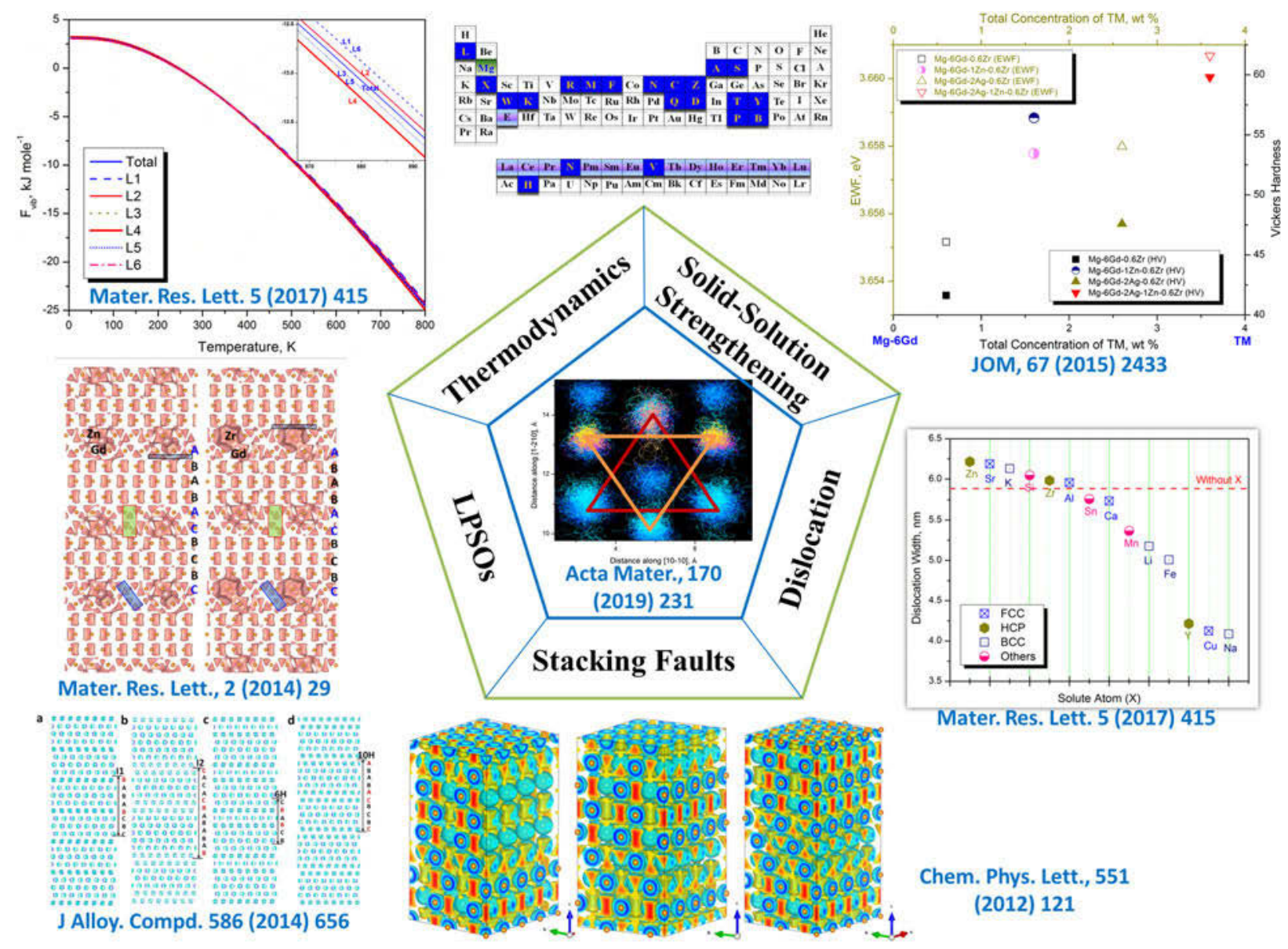

Figure 7: Strengthening and toughening strategies of $\mathrm{Mg}$ alloys based on first-principles properties repository.

deformation via either dislocation or affine/alias deformation $[95,104]$.

\section{Co-based superalloys}

In line with the aforementioned interface engineering strategy, the novel advanced Co-based superalloys can be potentially discovered by tailoring the local bonding environments, the macroscopic elastic and plastic properties, phase stabilities/ transformations, structural defects and so on [55, 57, 62]. As shown in Fig. 8, the physical natures of local phase transformations of APB and SISF have been characterized clearly by bonding charge density, which are $\mathrm{L}_{2} \rightarrow \mathrm{DO}_{22}$ and $\mathrm{Ll}_{2} \rightarrow$ $\mathrm{D}_{19}$, respectively. In particular, the tetrahedral bonds of the $\mathrm{L1}_{2}$ matrix are the same as the measured FCC $\mathrm{Al}$ ones [66], which transform into the " $\mathrm{S}$ " shape in the APB and the rodetype of HCP in SISF [69]. The effects of solutes on the energy of APB and SISF, the modulus, the lattice distortion, the magnetism, and the bonding are comprehensively investigated. On the one hand, it is highlighted that the lattice distortion optimization caused by solutes has been recognized as a key approach in the development of advanced structural materials $[105,106,107,109]$. A positive lattice misfit $(>)[110,111]$ will yield a better high-temperature strength than otherwise similar alloys with a negative misfit, which is probably an important factor making the strengthened Co-based superalloys for future high-temperature applications $[57,112]$. Due to a higher thermal expansion coefficient of the matrix, the alloys with a positive lattice misfit should exhibit a decreased misfit at the aging temperature $[57,113]$. At the temperatures close to the solvus temperature, the misfit drops even further due to the beginning dissolution of and the corresponding compositional changes of $[57,113]$. The lattice misfit can be adjusted effectively through controlling the partitioning of alloying elements in the Co-based superalloys [107, 114], which also yield anomalous bonding structures [i.e., "from heart to hand" feature of $\mathrm{Ti}$ and $\mathrm{Ta}$ in $\mathrm{Co}_{3} \mathrm{TM}$ in Fig. 8(a)], thus to optimize the deformation behaviors.

On the other hand, it is critical to understand/control the planar defect segregation behaviors of the solute atoms at the fault layers, which dominate the shearing mechanisms during creep. As shown in Fig. 8(b), the results of $E_{\text {SISF }}$ via the ANNI model are consistent with the classical. SISF-supercell method utilized in first-principles calculations provides the approach to efficiently distinguish various planar faults and predict their 


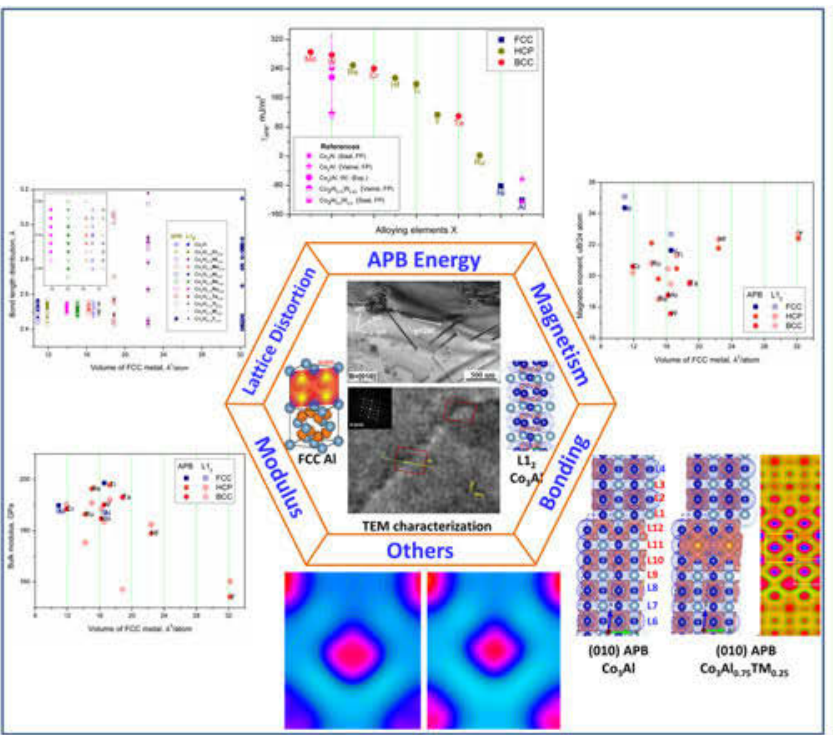

(a)

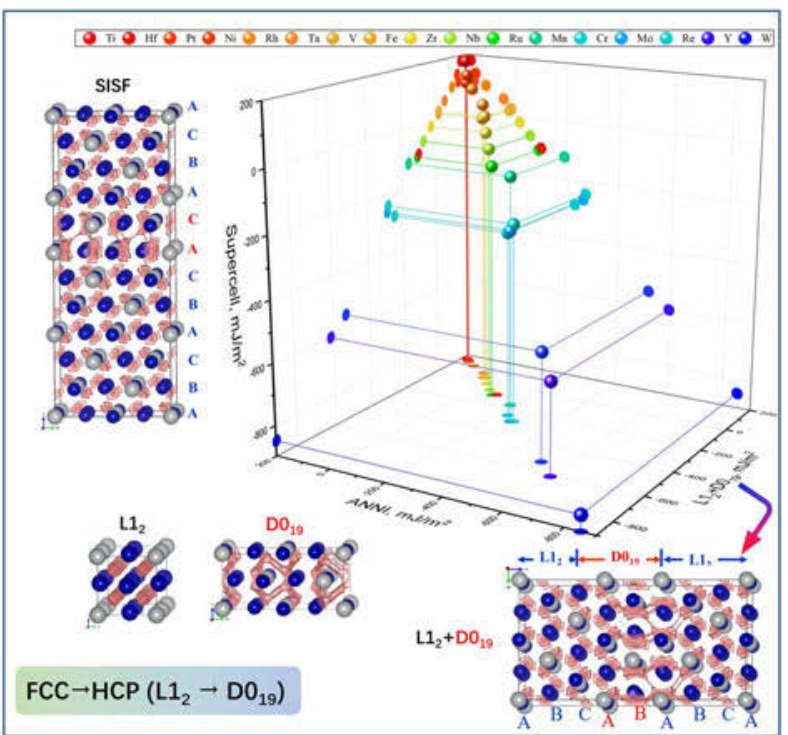

(b)

Figure 8: When defect is a pathway to improve stability of Co-based superalloys: (a) atomic and electronic basis for the solutes strengthened $L 1_{2} \mathrm{CO}_{3}(\mathrm{Al}, \mathrm{TM}) \mathrm{APB}$ [57] and (b) comparisons of $E_{\mathrm{SF}}$ values of $\mathrm{CO}_{3} \mathrm{TM}$ calculated by the SISF-supercell method, the ANNI model, and the $\mathrm{L1}_{2}+\mathrm{DO}_{19}$ model [62].

corresponding energies, such as SISF $[115,116]$, SESF $[115$, 116], and APB [57, 117], etc. [62]. It can be seen that interface/ defect engineering has been one of the important strategies in the development of advanced materials. In fact, interfaces/ defects not only affect the local bonding environment/strength at the atomic scale but also play a dominant role adjusting the macroscopic elastic and plastic properties. Motivated by the discovery of novel stable $\mathrm{L1}_{2} \mathrm{Co}_{3}(\mathrm{Al}, \mathrm{W})$ compound a decade ago [110] and the recent work entitled "When Defects are not Defects" [58], a great amount of efforts have been made in the investigations of its structural defects and phase transformations, the transformations of which dominate the performance of the material in service. Our recent works [57,62] suggest that controlling energies of planar defects (such as stacking faults and APBs) by alloying is critical for the development of advanced superalloys.

\section{Refractory high entropy alloys}

Lattice distortion/misfit has been set as one of the four hypotheses in the discovery of advanced high-entropy alloys, which can be caused by the atomic radius differences among various solute/solvent and the local chemical orders/disorders $[49,51]$. It is understood that local chemical orders play an important role in the mechanical properties of HEA, such as serrations, strengthening, and functional applications [33, 49, 51, 118, 119, 120]. Recently, improved experimental and theoretical tools to study short-range ordering effects have been highlighted [33]. Referring to the classical special quasirandom structures [121, 122, 123], the cluster-plus-glue-atom model can not only yield the identical random structures but also provide the ordered ones, supporting a strategy to reveal the effects of order-disorder configurational transitions on the properties of HEAs [49, 51]. As shown in Fig. 9(a), the configurational transitions are constructed for these BCC equiatomic refractory HEAs. In the view of $\Delta \rho$, the local lattice distortion caused by various group of elements results in the so-called weak spots, where there is few bonding electrons constructing the loose-packed regions. For example, the regions enriched of $\mathrm{Zr}$ atoms with the larger atomic radius in configuration R1 form weak spots [124], the bonding strength of which is very low. On the contrary, the tightly bonded clusters with higher value of $\Delta \rho$ display the physical nature of the solid-solution strengthening mechanism, contributing to the high strength of RHEAs [51]. Moreover, the responses of weak spot and cluster to the elastic and the plastic deformation are different. While the former of which results in a slip avalanche via the sudden burst of atomic motion [124] and structural rejuvenation [125], the latter one is hard to slip/ shear.

Furthermore, VEC has been treated as one key design principle in the discovery of new HEAs [64, 126, 127, 128]. For example, the formation of FCC- or BCC-type HEAs in a given multicomponent system can be estimated by the value of the VEC, which is $>7.5$ to 8 and $<6$ to 7.5 for FCC and BCC HEAs, respectively [51, 64, 127, 128]. Based on the aforementioned comparisons between VEC and EWF shown in Fig. 3, these two VEC criteria locate at the VIIB-VIIIB and the IVB-VIIB group elements constituting the equiatomic HEAs. In line with Fig. 9(b), it is worth to mention that the 


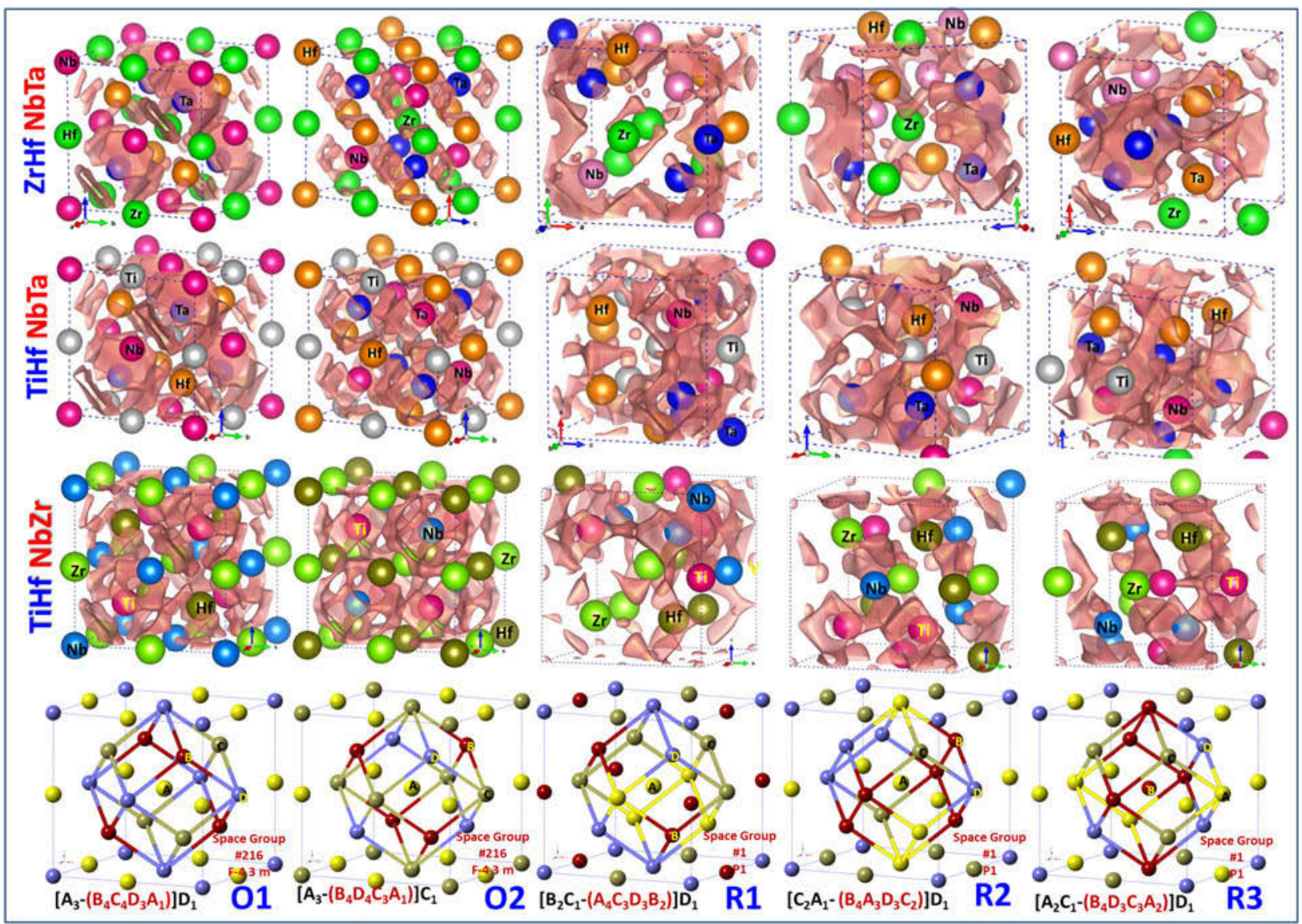

(a)

(b)
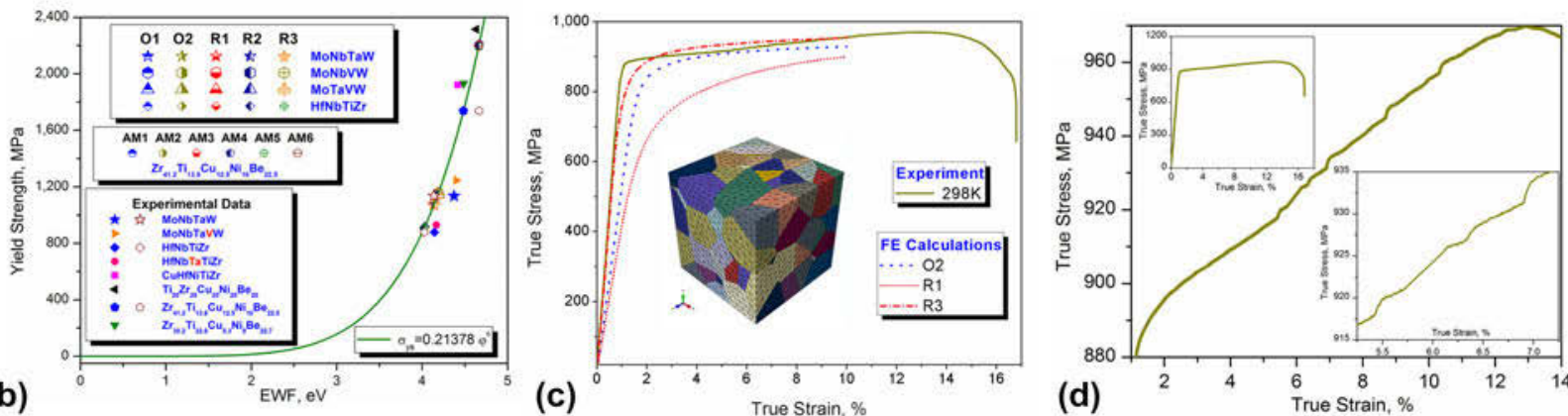

Figure 9: The atomic and electronic basis for the configurational transition dominated properties of RHEAs: (a) various microstates/configurations of ZrHfNbTa, TiHfNbTa, and TiHfNbZr alloys; (b) power-law scaled yield strength of HEAs [51]; and (c, d) the configurational transition dominated mechanical properties and the experimental serration behavior of TiHfNbZr [51].

power-law scaled mechanical properties, including hardness, yield strength, and Young's modulus, can be predicted in terms of EWF, which have been validated in pure elements [129, 130], Al alloys [70], HEAs [51], and vit-1 metallic glass [51]. Since the slip/shear process consists electronic redistributions during breaking and reforming chemical bonds, the variations in the first neighbor atoms in the slip planes would result in different microstates as shown in Fig. 9(a). Correspondingly, their effects on the yield strength of TiHfNbZr are presented in Fig. 9(c), which contribute to the experimentally observed serration behaviors in Fig. 9(d). Therefore, the atomic structure-dominated elastic and plastic properties can be predicted and revealed comprehensively by atoms and electrons [51]. It is expected that the integrations of multiscale simulations with the aid of principles/criteria, such as enthalpy of mixing $(\Delta H)$, entropy of mixing $(\Delta H)$, lattice distortion/misfit or atomic size difference $(\delta)$, and VEC/EWF, will be an effective strategy accelerating the discovery of advanced HEAs [51, 131, 132].

\section{Al alloys}

Because of their the high strength-to-weight ratio, recyclability, and resistance to corrosion, age-hardenable $\mathrm{Al}$ alloys are widely 
utilized in the aerospace, transport, automotive, and shipbuilding industries [133]. With the quick development of the highspeed railway and the service of the China Railway High-speed $(\mathrm{CRH})$ series for more than a decade, it is extremely important to manage/maintain those trains in service environmental conditions [61, 133]. Accordingly, the corrosion resistance of the utilized $\mathrm{Al}$ alloys is recommended to be tested strictly, such as the pitting corrosion, intergranular corrosion, and stress corrosion cracking. Since hydrogen is usually coupled with the structural defects (including vacancy, solutes, interfaces, and boundaries), hydrogen embrittlement (HE) has been considered as a serious industrial problem, overcompensating the energy cost to form defects, reducing the ductility and resulting in the brittle fracture $[134,135,136,137,138,139,140]$. It is noted that the stress corrosion cracking and corrosion fatigue/ fracture of high-strength $\mathrm{Al}$ alloys always involve hydrogen [141].

Figure 10 displays our recent works of the hydrogenmediated failure of $\mathrm{Al}, \mathrm{Al}_{98} \mathrm{H}_{2}$, and $\mathrm{Al}_{95} \mathrm{H}_{5}$ alloys by classical molecular dynamics simulations, investigating the effect of hydrogen on their deformation behavior and crack propagation under axial tension at a strain rate of $1 \times 10^{-9} \mathrm{~s}^{-1}$. As shown in Fig. 10(a), there is a severe lattice strain at the crack tip, which is characterized in terms of von Mises strain. During the tensile plastic deformation, the crack propagation paths (two groups of slip planes in red) of Al follow Schmid's law, yielding the angle between the tensile force and the slip plane to be $45^{\circ}$ and obtaining the maximum shear stresses along the slip planes. With the improved concentration of $\mathrm{H}$, there will be less shear/slip bands or dislocations in the $\mathrm{Al}$ matrix. Since the snapshots of $\mathrm{Al}, \mathrm{Al}_{98} \mathrm{H}_{2}$, and $\mathrm{Al}_{95} \mathrm{H}_{5}$ are selected with the same running time, it can been seen that both the cracking distance and the thickness of slip bands are improved with the enhanced concentration of $\mathrm{H}$, indicating the hydrogen-assisted cracking and the accelerated cracking rate. Through enlarging atomic radius of $\mathrm{H}$ atoms, higher than that of $\mathrm{Al}$ atoms, the trapped hydrogen activated crack propagation and slip of $\mathrm{Al}_{98} \mathrm{H}_{2}$ are represented obviously in Fig. 10(b). It can be seen that the enriched $\mathrm{H}$ atoms along the slip bands endure the higher von Mises strain and the bonding strength of which is weaker than the $\mathrm{Al}-\mathrm{Al}$ bond [61], dominating the cracking propagation paths. Thus, $\mathrm{H}$ atoms are always captured in each slip plane, especially at the tip highlighted by those ellipses in Fig. 10(c). Therefore, with electronic and atomic structures, the

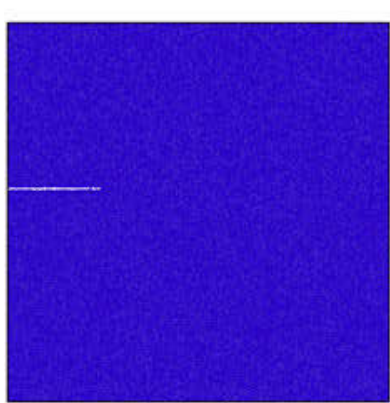

(a) Original

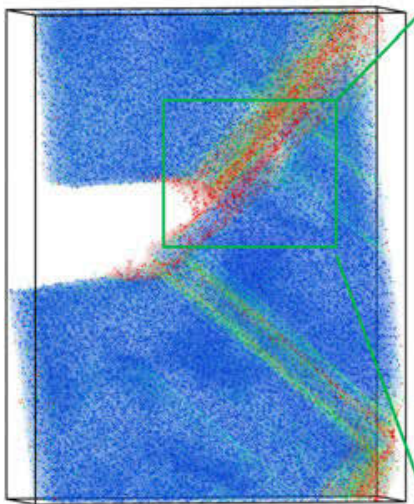

(b)

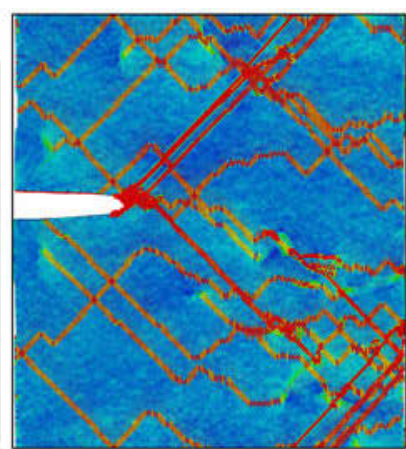

Al

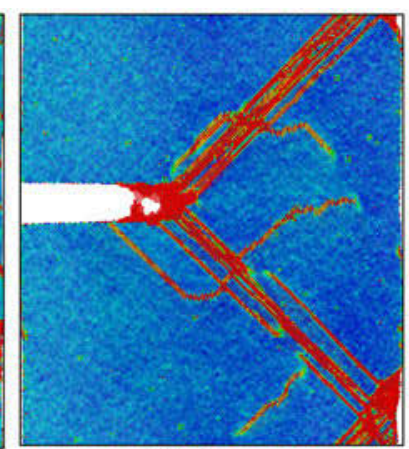

$\mathrm{Al}_{98} \mathrm{H}_{2}$

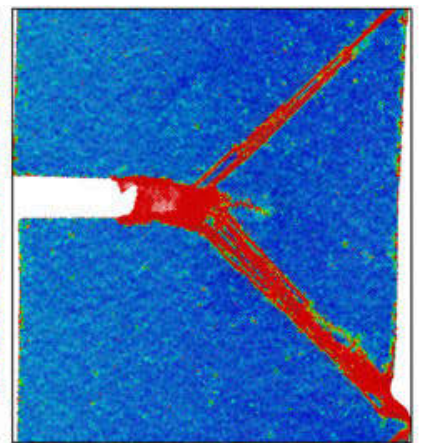

$\mathrm{Al}_{95} \mathrm{H}_{5}$

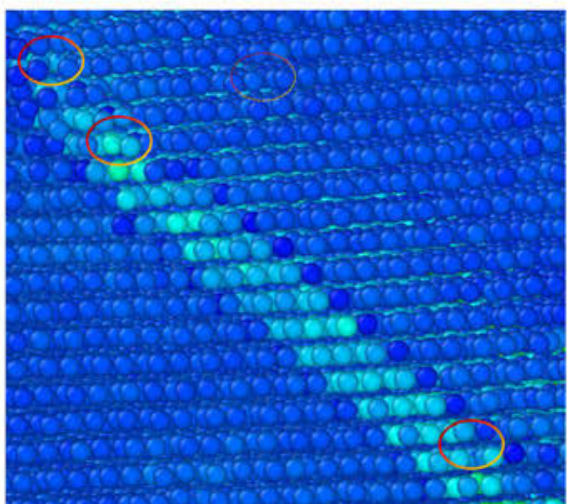

(c)

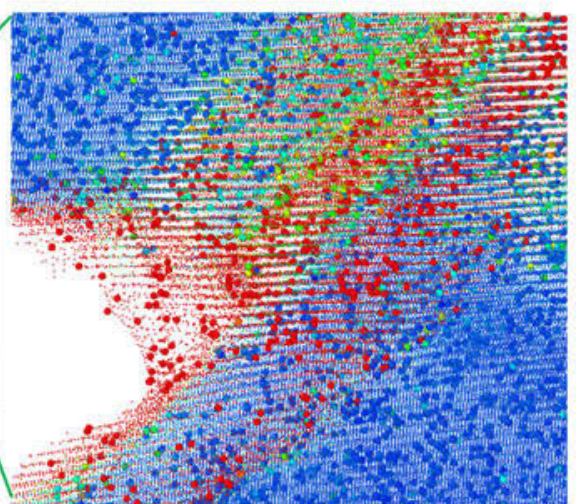

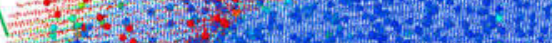

Figure 10: Hydrogen-mediated failure of Al and Al-H alloys and its electronic basis. (a) Effect of hydrogen on the deformation behavior and crack propagation of $\mathrm{Al}, \mathrm{Al}_{98} \mathrm{H}_{2}$, and $\mathrm{Al}_{95} \mathrm{H}_{5}$ under axial tension at a strain rate of $1 \times 10^{-9} \mathrm{~s}^{-1}$. (b) The trapped hydrogen activated crack propagation and slip of $\mathrm{Al}_{98} \mathrm{H}_{2}$ presenting an obvious contrast by enlarging atomic radius of $\mathrm{H}$ atoms than those of $\mathrm{Al}$ atoms. (c) The trapped hydrogen at the tip of the dislocation and the von Mises strain is utilized to present the BGR gradient colors with minimum and maximum values of 0.001 and 0.9 , respectively. 
mechanisms and models of hydrogen-induced damage in structural metal materials can be revealed clearly [53, 61, 142, 143, 144]. Recently, first-principles modeling of anisotropic anodic dissolution of metals and alloys in corrosive environments reveals a formula to specify the relationship between the electrode potential and the current density by considering the basic parameters of surface energy density and work function, providing a promising perspective for designing better corrosion-resistant alloys [144].

\section{Summary and outlooks}

In summary, a brief review of our case studies of data-driven ICME for intelligently discovering/optimizing advanced structural metal materials is presented, which include the light-weight materials ( $\mathrm{Ti}, \mathrm{Mg}$, and $\mathrm{Al}$ alloys), RHEAs, and superalloys for high temperature applications. The basic bonding in terms of topology and electronic structures is recommended to be considered as the building blocks/units constructing the microstructures of advanced materials. Data - the basic unit building block of database and advanced computational algorithms such as machine learning, data mining, deep learning, and artificial intelligence-have been recognized as the third essential digital resource in the $I^{3} \mathrm{M}$ beside the natural mineral materials and the financial funds. The flow chain of "Data-Cyber-Knowledge-Wisdom" presents the inheritable feature of the data in the frameworks of "Materials Genome," which is also highlighted in the Datadriven ICME designing paradigm of advanced materials. It is expected that the integration of knowledge-based multiscale modeling/simulations and the machine-learning self-knowledge base, materials design and discovery will be further accelerated $[145,146]$. More duties are called to contribute the developments of data repositories, platforms/standards, and the training of next-generation workforce. Particularly, training our next-generation workforce will be the long-term strategic plan of both MGI/MGE and ICME, thus to support the enrollment in traditional advanced materials programs and to propel the field forward [1, 10, 36, 147]. It is worth mentioning that several objectives/aspects were addressed for preparing the current, emerging, and future workforce, who are responsible for implementing the activities for accelerating discovery, development and deployment of new materials by utilizing their wide cross-section of knowledge and capabilities from other fields, i.e., chemistry, physics, biology, mathematics, computer science, data science, statistics, and information technology [1, 10, 36, 147]. Through building advanced algorithms in the development of a promising digital fabricating approach to address the present and future challenges, it is believed that the digital-twin intelligent manufacturing era is coming soon [2].

\section{Acknowledgments}

The authors acknowledge the financial supports from the National Key Research and Development Program of China (2016YFB0701304, 2016YFB0701303, 2018YFB0703801, and 2018YFB0703802), the National Natural Science Foundation of China (Grant No. 51690163), National Science and Technology Major Project (2017-VI-0014-0086), CRRC Tangshan Co., Ltd. (Contract No. 201750463031), Science Challenge Project (Contract No. TZZT2019-D1.5), project of SKL-AMMUSTB (Grant No. 2016-Z07), and Fundamental Research Funds for the Central Universities in China (G2016KY0302). Y. Zhang would like to thank the financial supports from the Seed Foundation of Innovation and Creation for Graduate Students at Northwestern Polytechnical University (ZZ2019081).

\section{References}

1. T.M. Pollock, J.E. Allison, D.G. Backman, M.C. Boyce, M. Gersh, E.A. Holm, R. Lesar, M. Long, A.C.P. IV, J.J. Schirra, D.D. Whitis, C. Woodward: Integrated Computational Materials Engineering: A Transformational Discipline for Improved Competitiveness and National Security (The National Academies, Washington, DC, 2008).

2. W.Y. Wang, J. Li, W. Liu, and Z-K. Liu: Integrated computational materials engineering for advanced materials: A brief review. Comput. Mater. Sci. 158, 42-48 (2019).

3. Z.K. Liu, L-Q. Chen, P. Raghavan, Q. Du, J.O. Sofo, S.A. Langer, and C. Wolverton: An integrated framework for multi-scale materials simulation and design. J. Comput.-Aided Mater. Des. 11, 183-199 (2005).

4. Z.K. Liu: A materials research paradigm driven by computation. JOM 61, 18-20 (2009).

5. D. Frankel, N. Hatcher, D. Snyder, J. Sebastian, G.B. Olson, G. Vernon, W. Everhart, and L. Carroll: Improving manufacturing quality using integrated computational materials engineering. In Proceedings of the $4^{\text {th }}$ World Congress on Integrated Computational Materials Engineering (Springer International Publishing Ag, Cham, 2017), pp. 23-32

6. National Academies of Sciences Engineering Medicine: Future Directions for NSF Advanced Computing Infrastructure to Support U.S. Science and Engineering in 2017-2020 (The National Academies Press, Washington D.C., 2016).

7. T.M. Pollock: Alloy design for aircraft engines. Nat. Mater. 15, 809-815 (2016).

8. D. Garcia, M.E. Jones, Y. Zhu, and H.Z. Yu: Mesoscale design of heterogeneous material systems in multi-material additive manufacturing. J. Mater. Res. 33, 58-67 (2018).

9. R. Jose and S. Ramakrishna: Materials 4.0: Materials big data enabled materials discovery. Appl. Mater. Today 10, 127-132 (2018). 
10. J.J. de Pablo, N.E. Jackson, M.A. Webb, L.Q. Chen, J.E. Moore, D. Morgan, R. Jacobs, T. Pollock, D.G. Schlom, E.S. Toberer, J. Analytis, I. Dabo, M. DeLongchamp, G.A. Fiete, G.M. Grason, G. Hautier, Y. Mo, K. Rajan, E.J. Reed, E.R.V. Stevanovic, J. Suntivich, K. Thornton, and J.C. Zhao: New frontiers for the materials genome initiative. npj Comput. Mater. 5, 41 (2019)

11. I. Tanaka, K. Rajan, and C. Wolverton: Data-centric science for materials innovation. MRS Bull. 43, 659-663 (2018).

12. Y. Liu, T. Zhao, W. Ju, and S. Shi: Materials discovery and design using machine learning. J Materiomics 3, 159-177 (2017).

13. National Research Council: Big Data in Materials Research and Development: Summary of a Workshop (The National Academies Press, Washington, DC, 2014).

14. X. Zhang, D. Pan, C. Zhao, and K. Li: MMOY: Towards deriving a metallic materials ontology from yago. Adv. Eng. Inf. 30, 687-702 (2016)

15. X. Zhang, X. Liu, X. Li, and D. Pan: MMKG: An approach to generate metallic materials knowledge graph based on DBpedia and Wikipedia. Comput. Phys. Commun. 211, 98-112 (2017).

16. M. Picklum and M. Beetz: MatCALO: Knowledge-enabled machine learning in materials science. Comput. Mater. Sci. 163, 50-62 (2019).

17. B. Meredig and C. Wolverton: A hybrid computationalexperimental approach for automated crystal structure solution. Nat. Mater. 12, 123-127 (2013).

18. G.B. Olson: Designing a new material world. Science 288, $993-$ 998 (2000).

19. W. Xiong and G.B. Olson: Cybermaterials: Materials by design and accelerated insertion of materials. npj Comput. Mater. 2, 15009 (2016).

20. W. Chen: High-throughput computing for accelerated materials discovery. In Computational Materials System Design, D. Shin and J. Saal, eds. (Springer International Publishing, Cham, 2017) pp. 169-191

21. J-C. Zhao: Combinatorial approaches as effective tools in the study of phase diagrams and composition-structure-property relationships. Prog Mater Sci 51, 557-631 (2006).

22. J-C. Zhao: A combinatorial approach for efficient mapping of phase diagrams and properties. J. Mater. Res. 16, 1565-1578 (2001).

23. M. Bedewy: Data-driven understanding of collective carbon nanotube growth by in situ characterization and nanoscale metrology. J. Mater. Res. 32, 153-165 (2017).

24. B-C. Zhou, W.Y. Wang, Z-K. Liu, and R. Arroyave: Chapter 8 -Electronics to phases of magnesium. In Integrated Computational Materials Engineering (ICME) for Metals: Concepts and Case Studies, M.F. Horstemeyer, ed. (John Wiley \& Sons, Hoboken, NJ, 2018) pp. 237-282.

25. L-F. Huang, B. Grabowski, J. Zhang, M-J. Lai, C.C. Tasan, S. Sandlöbes, D. Raabe, and J. Neugebauer: From electronic structure to phase diagrams: A bottom-up approach to understand the stability of titanium-transition metal alloys. Acta Mater. 113, 311-319 (2016).

26. P.E. Krajewski, L.G. Hector, Y. Qi, R.K. Mishra, A.K. Sachdev, A.F. Bower, and W.A. Curtin: Atoms to autos: A multi-scale approach to modeling aluminum deformation. JOM 63, 24-32 (2011).

27. G.B. Olson and C.J. Kuehmann: Materials genomics: From CALPHAD to flight. Scr. Mater. 70, 25-30 (2014).

28. National Science and Technology Council: Materials Genome Initiative for Global Competitiveness (Office of Science and Technology Policy, Washington DC, June 2011).

29. National Science \& Technology Council: Strategy for American Leadership in Advanced Manufacturing (Office of Science and Technology Policy, Washington DC, October 2018).

30. J. Zhou, P. Li, Y. Zhou, B. Wang, J. Zang, and L. Meng: Toward new-generation intelligent manufacturing. Engineering 4, 11-20 (2018).

31. R.Y. Zhong, X. Xu, E. Klotz, and S.T. Newman: Intelligent manufacturing in the context of industry 4.0: A review. Engineering 3, 616-630 (2018).

32. Foresight: The Future of Manufacturing: A New Era of Opportunity and Challenge for the UK (The Govenment office for Science, London, 2013).

33. E.P. George, D. Raabe, and R.O. Ritchie: High-entropy alloys. Nat. Rev. Mater. 4, 515-534 (2019).

34. X.D. Xiang, X. Sun, G. Briceño, Y. Lou, K-A. Wang, H. Chang, W.G. Wallace-Freedman, S-W. Chen, and P.G. Schultz: A combinatorial approach to materials discovery. Science 268, 1738-1740 (1995).

35. W.Y. Wang, P.X. Li , D.Y Lin , B. Tang, J. Wang, Q.M. Guan, Q. Ye, H.X Dai, J. Gao, H.C. Kou, H.F. Song, F. Zhou, J.J. Ma, Z.K. Liu, J.S. Li, W.M. Liu: DID code-A bridge connecting materials genome engineering database and inheritable integrated intelligence manufacturing. Engineering (in press).

36. X. Liu, D. Furrer, J. Kosters, and J. Holmes: Vision 2040: A Roadmap for Integrated, Multiscale Modeling and Simulation of Materials and Systems (NASA/CR -2018-219771. March 2018).

37. A. Aspuru-Guzik, K. Persson, and H. Tribukait-Vasconelos: Materials Acceleration Platform-Accelerating Advanced Energy Materials Discovery by Integrating High-Throughput Methods with Artificial Intelligence (Mission Innovation) (Canadian Institute for Advanced Research, 2018).

38. The Minerals, Metals Materials S: Modeling Across Scales: A Roadmapping Study for Connecting Materials Models and Simulations Across Length and Time Scales (TMS, Warrendale, PA, 2015).

39. D. Shin and J. Saal: Computational Materials System Design (Springer, Cham, 2018). 
40. National Science \& Technology Council: Strategy for American Leadership in Advanced Manufacturing (Office of Science and Technology Policy, Washington DC, October 2018).

41. Z-K. Liu: Perspective on materials genome (in Chinese). Chin. Sci. Bull. 58, 3618-3622 (2013).

42. L-Q. Chen: Phase-field method and materials genome initiative (MGI). Chin. Sci. Bull. 59, 1641-1645 (2014).

43. I.M. Robertson, C.A. Schuh, J.S. Vetrano, N.D. Browning, D.P. Field, D.J. Jensen, M.K. Miller, I. Baker, D.C. Dunand, R. Dunin-Borkowski, B. Kabius, T. Kelly, S. Lozano-Perez,

A. Misra, G.S. Rohrer, A.D. Rollett, M.L. Taheri,

G.B. Thompson, M. Uchic, X-L. Wang, and G. Was: Towards an integrated materials characterization toolbox. J. Mater. Res. 26, 1341-1383 (2011).

44. L. Kaufman and J. Agren: CALPHAD, first and second generation - birth of the materials genome. Scr. Mater. 70, 3-6 (2014).

45. S. Curtarolo, D. Morgan, K. Persson, J. Rodgers, and G. Ceder: Predicting crystal structures with data mining of quantum calculations. Phys. Rev. Lett. 91, 135503 (2003).

46. O. Eriksson: Searching for materials with reduced dimension. Nat. Nanotechnol. 13, 180-181 (2018).

47. C.D. Taylor, P. Lu, J. Saal, G.S. Frankel, and J.R. Scully: Integrated computational materials engineering of corrosion resistant alloys. npj Mater. Degrad. 2, 6 (2018).

48. J.E. Saal, S. Kirklin, M. Aykol, B. Meredig, and C. Wolverton: Materials design and discovery with high-throughput density functional theory: The open quantum materials database (OQMD). JOM 65, 1501-1509 (2013).

49. W.Y. Wang, J. Wang, D. Lin, C. Zou, Y. Wu, Y. Hu, S-L. Shang, K.A. Darling, Y. Wang, X. Hui, J. Li, L.J. Kecskes, P.K. Liaw, and Z-K. Liu: Revealing the microstates of bodycentered-cubic (BCC) equiatomic high entropy alloys. J. Phase Equilib. Diffus. 38, 404-415 (2017).

50. Z.W. Wu, M.Z. Li, W.H. Wang, and K.X. Liu: Hidden topological order and its correlation with glass-forming ability in metallic glasses. Nat. Commun. 6, 6035 (2015).

51. W.Y. Wang, S.L. Shang, Y. Wang, F. Han, K.A. Darling, Y. Wu, X. Xie, O.N. Senkov, J. Li, X.D. Hui, K.A. Dahmen, P.K. Liaw, L.J. Kecskes, and Z-K. Liu: Atomic and electronic basis for the serrations of refractory high-entropy alloys. $n p j$ Comput. Mater. 3, 23 (2017).

52. Z. Lei, X. Liu, Y. Wu, H. Wang, S. Jiang, S. Wang, X. Hui, Y. Wu, B. Gault, P. Kontis, D. Raabe, L. Gu, Q. Zhang, H. Chen, H. Wang, J. Liu, K. An, Q. Zeng, T-G. Nieh, and Z. Lu: Enhanced strength and ductility in a high-entropy alloy via ordered oxygen complexes. Nature 563, 546-550 (2018).

53. J. Hou, X-S. Kong, X. Wu, J. Song, and C.S. Liu: Predictive model of hydrogen trapping and bubbling in nanovoids in bcc metals. Nat. Mater. 18, 833-839 (2019).
54. A.L. Greer, Y.Q. Cheng, and E. Ma: Shear bands in metallic glasses. Mater. Sci. Eng., R 74, 71-132 (2013).

55. P. Ball: Four decades of materials developments transform society. MRS Bull. 38, 873-885 (2013).

56. W.Y. Wang, S.L. Shang, Y. Wang, K.A. Darling, L.J. Kecskes, S.N. Mathaudhu, X.D. Hui, and Z-K. Liu: Electronic structures of long periodic stacking order structures in Mg: A firstprinciples study. J. Alloys Compd. 586, 656-662 (2014)

57. W.Y. Wang, F. Xue, Y. Zhang, S-L. Shang, Y. Wang, K.A. Darling, L.J. Kecskes, J. Li, X. Hui, Q. Feng, and Z-K. Liu: Atomic and electronic basis for solutes strengthened (010) antiphase boundary of $\mathrm{L1}_{2} \mathrm{Co}_{3}(\mathrm{Al}, \mathrm{TM})$ : A comprehensive firstprinciples study. Acta Mater. 145, 30-40 (2018).

58. A.V. Krasheninnikov: When defects are not defects. Nat. Mater. 17, 757-758 (2018).

59. J.M. Kosterlitz: Nobel lecture: Topological defects and phase transitions. Rev. Mod. Phys. 89, 040501 (2017).

60. W.Y. Wang, S.L. Shang, Y. Wang, Y.J. Hu, K.A. Darling, L.J. Kecskes, S.N. Mathaudhu, X.D. Hui, and Z-K. Liu: Lattice distortion induced anomalous ferromagnetism and electronic structure in FCC Fe and Fe-TM $(\mathrm{TM}=\mathrm{Cr}, \mathrm{Ni}, \mathrm{Ta}$, and $\mathrm{Zr})$ alloys. Mater. Chem. Phys. 162, 748-756 (2015).

61. W.Y. Wang, C. Zou, D. Lin, J. Tang, L. Zhang, J. Sun, Q. Guan, B. Tang, J. Wang, H. Kou, J. Gao, H. Song, J. Ma, and J. Li: Interstitial triggered grain boundary embrittlement of Al-X (X = H, N, and O). Comput. Mater. Sci. 163, 241-247 (2019).

62. Y. Zhang, J. Li, W.Y. Wang, P. Li, B. Tang, J. Wang, H. Kou, S. Shang, Y. Wang, L.J. Kecskes, X. Hui, Q. Feng, and Z-K. Liu: When a defect is a pathway to improve stability: A case study of the $\mathrm{Ll}_{2} \mathrm{Co}_{3} \mathrm{TM}$ superlattice intrinsic stacking fault. J. Mater. Sci. 54, 13609-13618 (2019).

63. S. Halas and T. Durakiewicz: Work functions of elements expressed in terms of the Fermi energy and the density of free electrons. J. Phys.: Condens. Matter 10, 10815 (1998).

64. S. Guo and C.T. Liu: Phase stability in high entropy alloys: Formation of solid-solution phase or amorphous phase. Prog. Nat. Sci. 21, 433-446 (2011).

65. Y. Wang, W.Y. Wang, L-Q. Chen, and Z-K. Liu: Bonding charge density from atomic perturbations. J. Comput. Chem. 36, 1008-1014 (2015).

66. P.N.H. Nakashima, A.E. Smith, J. Etheridge, and B.C. Muddle: The bonding electron density in aluminum. Science 331, 15831586 (2011).

67. W.Y. Wang, Y. Wang, S.L. Shang, K.A. Darling, H. Kim, B. Tang, H.C. Kou, S.N. Mathaudhu, X.D. Hui, J.S. Li, L.J. Kecskes, and Z-K. Liu: Strengthening Mg by self-dispersed nano-lamellar faults. Mater. Res. Lett. 5, 415-425 (2017).

68. B. Silvi and A. Savin: Classification of chemical-bonds based on topological analysis of electron localization functions. Nature 371, 683-686 (1994) 
69. W.Y. Wang, S.L. Shang, Y. Wang, K.A. Darling,

S.N. Mathaudhu, X.D. Hui, and Z.K. Liu: Electron localization morphology of the stacking faults in Mg: A first-principles study. Chem. Phys. Lett. 551, 121-125 (2012).

70. W.Y. Wang, K.A. Darling, Y. Wang, S-L. Shang, L.J. Kecskes, X.D. Hui, and Z-K. Liu: Power law scaled hardness of Mn strengthened nanocrystalline AlMn non-equilibrium solid solutions. Scr. Mater. 120, 31-36 (2016).

71. Y. Wang, Y. Kang, W.Y. Wang, Q. Ding, J. Zhou, and S. Yang: Circumventing silver oxidation induced performance degradation of silver surface-enhanced Raman scattering substrates. Nanotechnology 29, 414001 (2018).

72. Y.J. Hu, Y. Wang, W.Y. Wang, K.A. Darling, L.J. Kecskes, and Z.K. Liu: Solute effects on the $\Sigma 3$ (111)[110] tilt grain boundary in BCC Fe: Grain boundary segregation, stability, and embrittlement. Comput. Mater. Sci. 171, 109271 (2020).

73. W.Y. Wang, Y. Zhang, J. Li, C. Zou, B. Tang, H. Wang, D. Lin, J. Wang, H. Kou, and D. Xu: Insight into solid-solution strengthened bulk and stacking faults properties in Ti alloys: A comprehensive first-principles study. J. Mater. Sci. 53, 7493-7505 (2018).

74. C. Zou, J. Li, W.Y. Wang, Y. Zhang, B. Tang, H. Wang, D. Lin,

J. Wang, H. Kou, and D. Xu: Revealing the local lattice strains and strengthening mechanisms of Ti alloys. Comput. Mater. Sci. 152, 169-177 (2018).

75. V.R. Manga, S-L. Shang, W.Y. Wang, Y. Wang, J. Liang, V.H. Crespi, and Z-K. Liu: Anomalous phonon stiffening associated with the (111) antiphase boundary in $\mathrm{Ll}_{2} \mathrm{Ni}_{3} \mathrm{Al}$. Acta Mater. 82, 287-294 (2015).

76. H. Kim, W.Y. Wang, S-L. Shang, L.J. Kecskes, K.A. Darling, and Z-K. Liu: Elastic properties of long periodic stacking ordered phases in Mg-Gd-Al alloys: A first-principles study. Intermetallics 98, 18-27 (2018).

77. W.Y. Wang, J.J. Han, H.Z. Fang, J. Wang, Y.F. Liang, S.L. Shang, Y. Wang, X.J. Liu, L.J. Kecskes, S.N. Mathaudhu, X. Hui, and Z.K. Liu: Anomalous structural dynamics in liquid $\mathrm{Al}_{80} \mathrm{Cu}_{20}$ : An ab initio molecular dynamics study. Acta Mater. 97, 75-85 (2015).

78. Y. Wang, L. Zhao, Y. Zhao, W.Y. Wang, Y. Liu, C. Gu, J. Li, G. Zhang, T.J. Huang, and S. Yang: Electrocarving during electrodeposition growth. Adv. Mater. 30, 1805686 (2018).

79. S.L. Shang, Y. Wang, P. Guan, W.Y. Wang, H. Fang, T. Anderson, and Z-K. Liu: Insight into structural, elastic, phonon, and thermodynamic properties of $\alpha$-sulfur and energyrelated sulfides: A comprehensive first-principles study. J. Mater. Chem. A 3, 8002-8014 (2015).

80. S. Yang, B. Kiraly, W.Y. Wang, S. Shang, B. Cao, H. Zeng, Y. Zhao, W. Li, Z-K. Liu, W. Cai, and T.J. Huang: Fabrication and characterization of beaded $\mathrm{SiC}$ quantum rings with anomalous red spectral shift. Adv. Mater. 24, 5598-5603 (2012).
81. S-L. Shang, J. Shimanek, S. Qin, Y. Wang, A.M. Beese, and Z-K. Liu: Unveiling dislocation characteristics in $\mathrm{Ni}_{3} \mathrm{Al}$ from stacking fault energy and ideal strength: A first-principles study via pure alias shear deformation. Phys. Rev. B 101, 024102 (2020).

82. Y-J. Hu, G. Zhao, B. Zhang, C. Yang, M. Zhang, Z-K. Liu, X. Qian, and L. Qi: Local electronic descriptors for solute-defect interactions in bcc refractory metals. Nat. Commun. 10, 4484 (2019).

83. S.H. Zhang, I.J. Beyerlein, D. Legut, Z.H. Fu, Z. Zhang, S.L. Shang, Z.K. Liu, T.C. Germann, and R.F. Zhang: Firstprinciples investigation of strain effects on the stacking fault energies, dislocation core structure, and Peierls stress of magnesium and its alloys. Phys. Rev. B 95, 224106 (2017).

84. D.G. Sangiovanni, L. Hultman, and V. Chirita:

Supertoughening in B1 transition metal nitride alloys by increased valence electron concentration. Acta Mater. 59, 21212134 (2011).

85. F. Giustino: Materials Modeling Using Density Functional Theory-Properties and Predictions (Oxford University Press, Oxford, 2014).

86. D. Banerjee and J.C. Williams: Perspectives on titanium science and technology. Acta Mater. 61, 844-879 (2013).

87. C.E. Wen, Y. Yamada, K. Shimojima, Y. Chino, H. Hosokawa, and M. Mabuchi: Novel titanium foam for bone tissue engineering. J. Mater. Res. 17, 2633-2639 (2002).

88. M.E. Kassner: Fundamentals of Creep in Metals and Alloys, 2nd ed. (Elsevier, Amsterdam, 2009)

89. A.A. Salem, S.R. Kalidindi, and R.D. Doherty: Strain hardening of titanium: Role of deformation twinning. Acta Mater. 51, 42254237 (2003).

90. M.H. Yoo: Slip, twinning, and fracture in hexagonal close-packed metals. Metall. Trans. A 12, 409-418 (1981).

91. Q-M. Hu and R. Yang: Basal-plane stacking fault energy of hexagonal close-packed metals based on the Ising model. Acta Mater. 61, 1136-1145 (2013).

92. H. Van Swygenhoven, P.M. Derlet, and A.G. Froseth: Stacking fault energies and slip in nanocrystalline metals. Nat. Mater. 3, 399-403 (2004).

93. S.L. Shang, W.Y. Wang, B.C. Zhou, Y. Wang, K.A. Darling, L.J. Kecskes, S.N. Mathaudhu, and Z.K. Liu: Generalized stacking fault energy, ideal strength and twinnability of dilute Mg-based alloys: A first-principles study of shear deformation. Acta Mater. 67, 168-180 (2014).

94. R. Salloom, R. Banerjee, and S.G. Srinivasan: Effect of betastabilizer elements on stacking faults energies and ductility of alpha-titanium using first-principles calculations. J. Appl. Phys. 120, 175105 (2016).

95. W.Y. Wang, B. Tang, S-L. Shang, J. Wang, S. Li, Y. Wang, J. Zhu, S. Wei, J. Wang, K.A. Darling, S.N. Mathaudhu, Y. Wang, Y. Ren, X.D. Hui, L.J. Kecskes, J. Li, and Z-K. Liu: Local lattice distortion mediated formation of 
stacking faults in Mg alloys. Acta Mater. 170, 231-239 (2019).

96. K. Lu: The future of metals. Science 328, 319-320 (2010).

97. G. Wu, K-C. Chan, L. Zhu, L. Sun, and J. Lu: Dual-phase nanostructuring as a route to high-strength magnesium alloys. Nature 545, 80-83 (2017).

98. Q. Yu, L. Qi, R.K. Mishra, J. Li, and A.M. Minor: Reducing deformation anisotropy to achieve ultrahigh strength and ductility in $\mathrm{Mg}$ at the nanoscale. Proc. Natl. Acad. Sci. U. S. A. 110, 13289-13293 (2013).

99. W.Y. Wang, S.L. Shang, Y. Wang, H. Kim, K.A. Darling, L.J. Kecskes, S.N. Mathaudhu, X.D. Hui, and Z-K. Liu: Solidsolution hardening in $\mathrm{Mg}-\mathrm{Gd}-\mathrm{TM}(\mathrm{TM}=\mathrm{Ag}, \mathrm{Zn}$, and $\mathrm{Zr}$ ) alloys: An integrated density functional theory and electron work function study. JOM 67, 2433-2441 (2015).

100. W.Y. Wang, S.L. Shang, Y. Wang, Z-G. Mei, K.A. Darling, L.J. Kecskes, S.N. Mathaudhu, X.D. Hui, and Z-K. Liu: Effects of alloying elements on stacking faults energies and electronic structures of binary Mg alloys: A first-principles study. Mater. Res. Lett. 2, 29-36 (2014).

101. W.W. Jian, G.M. Cheng, W.Z. Xu, H. Yuan, M.H. Tsai, Q.D. Wang, C.C. Koch, Y.T. Zhu, and S.N. Mathaudhu: Ultrastrong Mg alloy via nano-spaced stacking faults. Mater. Res. Lett. 1, 61-66 (2013).

102. J.F. Nie, Y.M. Zhu, J.Z. Liu, and X.Y. Fang: Periodic segregation of solute atoms in fully coherent twin boundaries. Science 340, 957-960 (2013).

103. X. Zhao, H. Chen, N. Wilson, Q. Liu, and J-F. Nie: Direct observation and impact of co-segregated atoms in magnesium having multiple alloying elements. Nat. Commun. 10, 3243 (2019).

104. T. Saito, T. Furuta, J.H. Hwang, S. Kuramoto, K. Nishino, N. Suzuki, R. Chen, A. Yamada, K. Ito, Y. Seno, T. Nonaka, H. Ikehata, N. Nagasako, C. Iwamoto, Y. Ikuhara, and

T. Sakuma: Multifunctional alloys obtained via a dislocation-free plastic deformation mechanism. Science 300, 464-467 (2003).

105. S. Jiang, H. Wang, Y. Wu, X. Liu, H. Chen, M. Yao, B. Gault, D. Ponge, D. Raabe, A. Hirata, M. Chen, Y. Wang, and Z. Lu: Ultrastrong steel via minimal lattice misfit and high-density nanoprecipitation. Nature 544, 460-464 (2017).

106. L. Vitos, I.A. Abrikosov, and B. Johansson: Anisotropic lattice distortions in random alloys from first-principles theory. Phys. Rev. Lett. 87, 156401 (2001).

107. S. Meher, L.J. Carroll, T.M. Pollock, and M.C. Carroll: Solute partitioning in multi-component $\gamma / \gamma^{\prime}$ Co-Ni-base superalloys with near-zero lattice misfit. Scr. Mater. 113, 185-189 (2016).

108. D.R. Trinkle and C. Woodward: The chemistry of deformation: How solutes soften pure metals. Science 310, 1665-1667 (2005).

109. C.H. Zenk, S. Neumeier, H.J. Stone, and M. Goken: Mechanical properties and lattice misfit of $\gamma / \gamma^{\prime}$ strengthened Co-base superalloys in the $\mathrm{Co}-\mathrm{W}-\mathrm{Al}-\mathrm{Ti}$ quaternary system. Intermetallics 55, 28-39 (2014).

110. J. Sato, T. Omori, K. Oikawa, I. Ohnuma, R. Kainuma, and K. Ishida: Cobalt-base high-temperature alloys. Science 312, 9091 (2006).

111. M.S. Titus, A. Mottura, G. Babu Viswanathan, A. Suzuki, M.J. Mills, and T.M. Pollock: High resolution energy dispersive spectroscopy mapping of planar defects in $\mathrm{L}_{2}$-containing Cobase superalloys. Acta Mater. 89, 423-437 (2015).

112. H. Mughrabi: The importance of sign and magnitude of $\gamma / \gamma^{\prime}$ lattice misfit in superalloys-with special reference to the new $\gamma^{\prime}$-hardened cobalt-base superalloys. Acta Mater. 81, 21-29 (2014).

113. I. Povstugar, C.H. Zenk, R. Li, P-P. Choi, S. Neumeier, O. Dolotko, M. Hoelzel, M. Göken, and D. Raabe: Elemental partitioning, lattice misfit and creep behaviour of $\mathrm{Cr}$ containing $\gamma^{\prime}$ strengthened Co base superalloys. Mater. Sci. Technol. 32, 220225 (2016)

114. S. Meher, H.Y. Yan, S. Nag, D. Dye, and R. Banerjee: Solute partitioning and site preference in $\gamma / \gamma^{\prime}$ cobalt-base alloys. Scr. Mater. 67, 850-853 (2012)

115. P.J.H. Denteneer and W.V. Haeringen: Stacking-fault energies in semiconductors from first-principles calculations. J. Phys. C: Solid State Phys. 20, L883-L887 (1987).

116. M. Chandran and S.K. Sondhi: First-principle calculation of stacking fault energies in $\mathrm{Ni}$ and Ni-Co alloy. J. Appl. Phys. 109, 103525 (2011).

117. C. Colinet and A. Pasturel: Structural stability of onedimensional long-period structures in the $\mathrm{TiAl}_{3}$ compound. J. Phys.: Condens. Matter 14, 6713 (2002).

118. Q. Ding, Y. Zhang, X. Chen, X. Fu, D. Chen, S. Chen, L. Gu, F. Wei, H. Bei, Y. Gao, M. Wen, J. Li, Z. Zhang, T. Zhu, R.O. Ritchie, and Q. Yu: Tuning element distribution, structure and properties by composition in high-entropy alloys. Nature 574, 223-227 (2019).

119. M.C. Gao, D.B. Miracle, D. Maurice, X. Yan, Y. Zhang, and J.A. Hawk: High-entropy functional materials. J. Mater. Res. 33, 3138-3155 (2018).

120. J-W. Yeh and S-J. Lin: Breakthrough applications of highentropy materials. J. Mater. Res. 33, 3129-3137 (2018).

121. A. Zunger, S.H. Wei, L.G. Ferreira, and J.E. Bernard: Special quasirandom structures. Phys. Rev. Lett. 65, 353-356 (1990).

122. C. Jiang, C. Wolverton, J. Sofo, L-Q. Chen, and Z-K. Liu: Firstprinciples study of binary bcc alloys using special quasirandom structures. Phys. Rev. B 69, 214202 (2004).

123. M.C. Gao, J-W. Yeh, P.K. Liaw, and Y. Zhang: High-Entropy Alloys: Fundamentals and Applications (Springer International Publishing, Cham, 2016).

124. K.A. Dahmen, Y. Ben-Zion, and J.T. Uhl: A simple analytic theory for the statistics of avalanches in sheared granular materials. Nat. Phys. 7, 554-557 (2011). 
125. E. Ma: Tuning order in disorder. Nat. Mater. 14, 547-552 (2015).

126. M.C. Troparevsky, J.R. Morris, P.R.C. Kent, A.R. Lupini, and G.M. Stocks: Criteria for predicting the formation of single-phase high-entropy alloys. Phys. Rev. X 5, 011041 (2015).

127. Y. Zhang, T.T. Zuo, Z. Tang, M.C. Gao, K.A. Dahmen,

P.K. Liaw, and Z.P. Lu: Microstructures and properties of highentropy alloys. Prog. Mater. Sci. 61, 1-93 (2014).

128. M.G. Poletti and L. Battezzati: Electronic and thermodynamic criteria for the occurrence of high entropy alloys in metallic systems. Acta Mater. 75, 297-306 (2014).

129. G. Hua and D. Li: Generic relation between the electron work function and Young's modulus of metals. Appl. Phys. Lett. 99, 041907 (2011).

130. G. Hua and D. Li: The correlation between the electron work function and yield strength of metals. Phys. Status Solidi B 249, 1517-1520 (2012)

131. O.N. Senkov, J.D. Miller, D.B. Miracle, and C. Woodward: Accelerated exploration of multi-principal element alloys with solid solution phases. Nat. Commun. 6, 6529 (2015).

132. M. Gao and D. Alman: Searching for next single-phase highentropy alloy compositions. Entropy 15, 4504-4519 (2013).

133. Q. Guan, J. Sun, W. Wang, J. Gao, C. Zou, J. Wang, B. Tang, H. Kou, H. Wang, J. Hou, J. Gao, J. Ma, and J. Li: Pitting corrosion of natural aged $\mathrm{Al}-\mathrm{Mg}-\mathrm{Si}$ extrusion profile. Materials 12, 1081 (2019).

134. D. Xie, S. Li, M. Li, Z. Wang, P. Gumbsch, J. Sun, E. Ma, J. Li, and Z. Shan: Hydrogenated vacancies lock dislocations in aluminium. Nat. Commun. 7, 13341 (2016).

135. X. Zhou, D. Marchand, D.L. McDowell, T. Zhu, and J. Song: Chemomechanical origin of hydrogen trapping at grain boundaries in fcc metals. Phys. Rev. Lett. 116, 075502 (2016).

136. X. Zhou and J. Song: Effect of local stress on hydrogen segregation at grain boundaries in metals. Mater. Lett. 196, 123127 (2017).
137. C. Wolverton, V. Ozolin, and M. Asta: Hydrogen in aluminum: First-principles calculations of structure and thermodynamics. Phys. Rev. B 69, 144109 (2004).

138. G. Lu and E. Kaxiras: Hydrogen embrittlement of aluminum: The crucial role of vacancies. Phys. Rev. Lett. 94, 155501 (2005).

139. J. Song and W.A. Curtin: Atomic mechanism and prediction of hydrogen embrittlement in iron. Nat. Mater. 12, 145-151 (2013).

140. H. Gunaydin, S.V. Barabash, K.N. Houk, and V. Ozolins: Firstprinciples theory of hydrogen diffusion in aluminum. Phys. Rev. Lett. 101, 075901 (2008).

141. N. Ben Ali, D. Tanguy, and R. Estevez: Effects of microstructure on hydrogen-induced cracking in aluminum alloys. Scr. Mater. 65, 210-213 (2011)

142. E.P. Georgiou, V.P. Cevallos, T. Van der Donck, D. Drees, J. Meersschaut, C.N. Panagopoulos, and J-P. Celis: Effect of cathodic hydrogen charging on the wear behavior of $5754 \mathrm{Al}$ alloy. Wear 390-391, 295-301 (2017).

143. D. Tanguy, B. Bayle, R. Dif, and T. Magnin: Hydrogen effects during IGSCC of pure $\mathrm{Al}-5 \mathrm{Mg}$ alloy in $\mathrm{NaCl}$ media. Corros. Sci. 44, 1163-1175 (2002).

144. O. Isayev, C. Oses, C. Toher, E. Gossett, S. Curtarolo, and A. Tropsha: Universal fragment descriptors for predicting properties of inorganic crystals. Nat. Commun. 8, 15679 (2017).

145. M. Umehara, H.S. Stein, D. Guevarra, P.F. Newhouse,

D.A. Boyd, and J.M. Gregoire: Analyzing machine learning models to accelerate generation of fundamental materials insights. npj Comput. Mater. 5, 34 (2019).

146. J.E. Gubernatis and T. Lookman: Machine learning in materials design and discovery: Examples from the present and suggestions for the future. Phys. Rev. Mater. 2, 120301 (2018).

147. The Minerals Metals \& Materials Society: Creating the NextGeneration Materials Genome Initiative Workforce. (The Minerals, Metals \& Materials Society, Pittsburgh, PA, 2019). 